\title{
WestVirginiaUniversity
}

THE RESEARCH REPOSITORY @ WVU

Graduate Theses, Dissertations, and Problem Reports

1999

\section{Experiential avoidance and alcohol dependence relapse}

Darrah Ann Westrup
West Virginia University

Follow this and additional works at: https://researchrepository.wvu.edu/etd

\section{Recommended Citation}

Westrup, Darrah Ann, "Experiential avoidance and alcohol dependence relapse" (1999). Graduate Theses, Dissertations, and Problem Reports. 3171.

https://researchrepository.wvu.edu/etd/3171

This Dissertation is protected by copyright and/or related rights. It has been brought to you by the The Research Repository @ WVU with permission from the rights-holder(s). You are free to use this Dissertation in any way that is permitted by the copyright and related rights legislation that applies to your use. For other uses you must obtain permission from the rights-holder(s) directly, unless additional rights are indicated by a Creative Commons license in the record and/ or on the work itself. This Dissertation has been accepted for inclusion in WVU Graduate Theses, Dissertations, and Problem Reports collection by an authorized administrator of The Research Repository @ WVU.

For more information, please contact researchrepository@mail.wvu.edu. 


\title{
Experiential Avoidance and Alcohol Dependence Relapse \\ Darrah Westrup
}

\author{
Dissertation submitted to the \\ Eberly College of Arts and Sciences \\ at West Virginia University \\ in partial fulfillment of the requirements \\ for the degree of
}

Doctor of Philosophy

in

Clinical Psychology

\author{
William Fremouw, Ph.D., Chair \\ Stan Cohen, Ph.D. \\ Georg Eifert, Ph.D. \\ Kevin Larkin, Ph.D. \\ Rollyn Sullivan, M.D. \\ Department of Psychology \\ Morgantown, West Virginia
}

1999

Keywords: Experiential Avoidance, Alcohol Dependence, Relapse

Copyright 1999, Darrah Westrup 


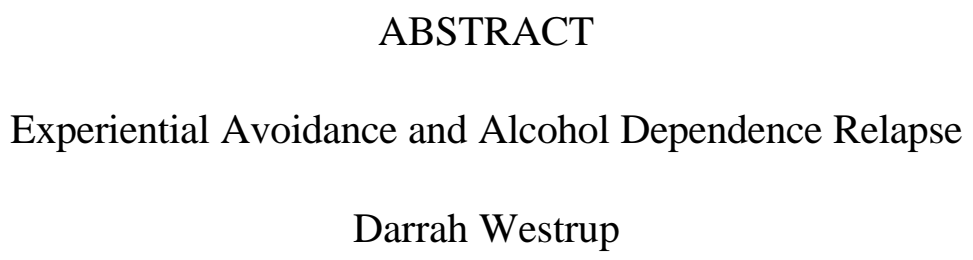

This project examined whether experiential avoidance differentiated alcohol-dependent relapsers from non-relapsers. Eighty-five subjects receiving inpatient addiction treatment were assessed for degree of experiential avoidance (using a new measure called the AAQ), coping style, alcohol severity, anxiety, and depression. It was hypothesized that the AAQ, along with avoidant coping and negative life events, would differentiate those who subsequently relapsed with those who did not. Three months after discharge, subjects were contacted for follow-up to determine whether or not they had relapsed, and to what degree they had experienced negative and/or positive life events. A series of discriminant function analyses determined that the AAQ failed to differentiate the 33 subjects who relapsed from the 38 who did not. In addition, relapsers did not differ from non-relapsers in terms of coping style. However, negative life events significantly differentiated the two outcome groups, with relapsers experiencing significantly more negative life events than non-relapsers. In addition, experientially avoidant individuals who experienced negative life events were more likely to relapse than were less avoidant individuals who also experienced negative life events. Other significant predictor variables were subjects' age (with younger subjects more likely to relapse), and anxiety symptoms (relapsers were more anxious than non-relapsers). These findings are discussed and followed with suggestions for future endeavors in the area of experiential avoidance and alcohol dependence relapse. 


\section{Acknowledgments}

I will take this opportunity to express my appreciation for those who provided assistance and support for this project and myself. First, I thank my dissertation committee members, who demonstrated extraordinary scholarship, mentoring, and integrity throughout my graduate years at WVU. I was proud to have you serve on my committee and prouder yet to have your sign-off signatures on this project. Based upon the model you provided, I hope to exert a similar positive influence in my future endeavors.

I also thank the excellent addiction treatment services staff at Chestnut Ridge Hospital and Preston Memorial Hospital. Under the expert direction of Dr. Rollyn Sullivan and Robert Kaschak, these programs proved to be outstanding resources and essentially made this project possible.

Special appreciation goes to my wonderful advisor and friend, Dr. William Fremouw. Your practical, sage advice has been invaluable. Most meaningful however, was your innate kindness and sense of fairness. Your influence has been significant throughout this experience and many others we have shared. I am pleased to be your friend.

And finally, a loving hug to my dear husband Andrew, who had no idea what he was getting into when he chose to marry me during the final stages of this project. Aside from your wonderful ability to double check scoring while watching a football game, the late night graham crackers and milk pulled me through. Thank you for your unfailing support. 


\section{Table of Contents}

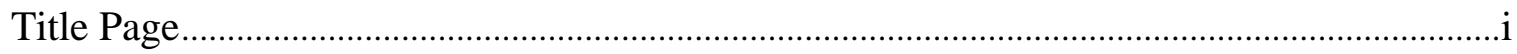

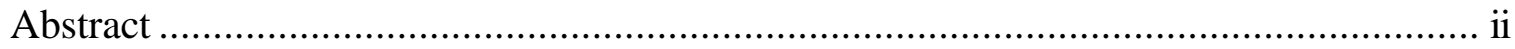

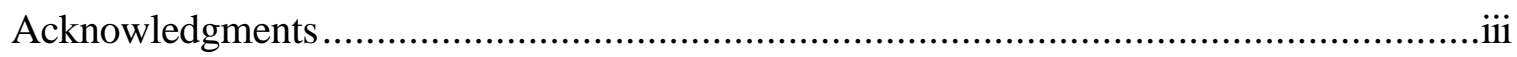

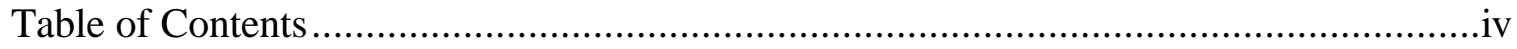

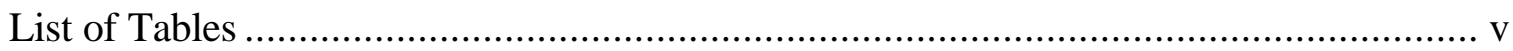

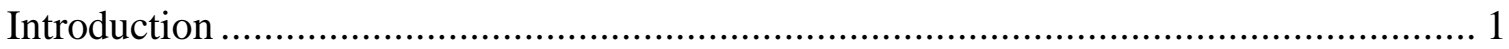

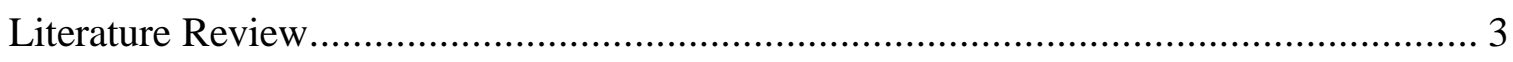

Alcohol Dependence Relapse .................................................................. 3

Negative Affect and Relapse ............................................................ 5

Life Events and Relapse....................................................................... 8

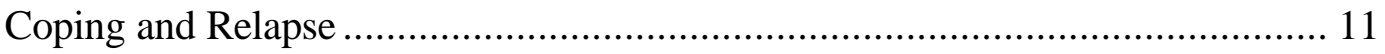

Demographics and Relapse ............................................................ 15

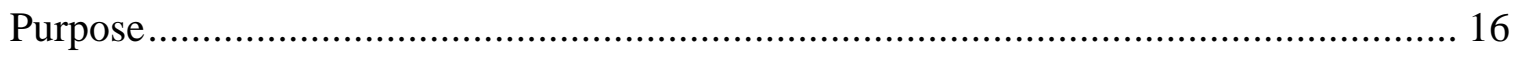

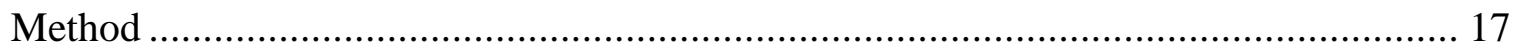

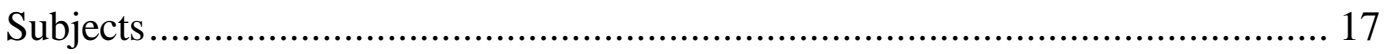

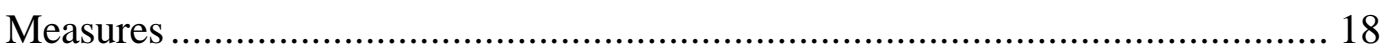

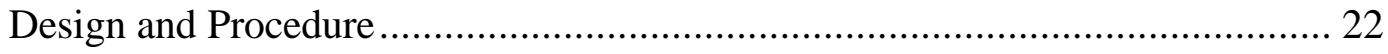

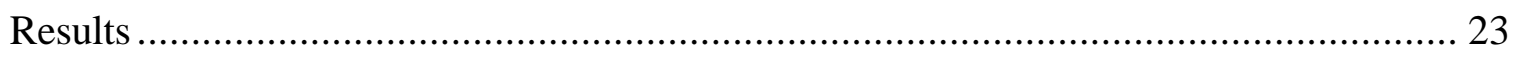

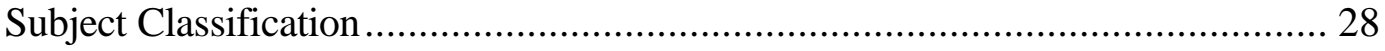

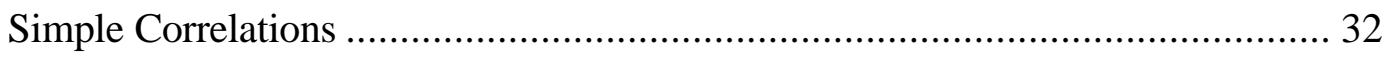

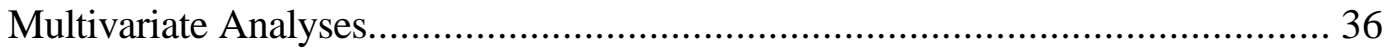

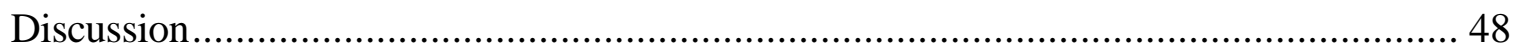




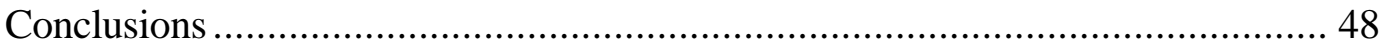

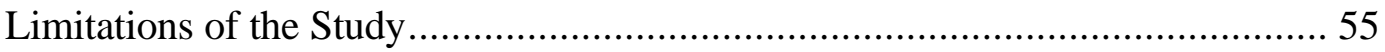

Summary and Future Directions .............................................................. 57

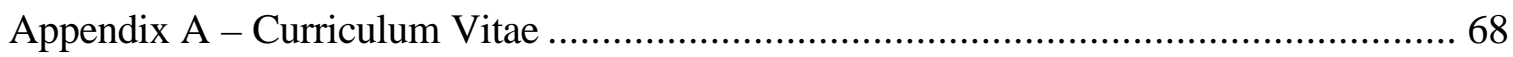




\section{List of Tables}

Table 1. Sample Size, Attrition, and Relapse Information by Site ......................................... 24

Table 2. Variables with Imputed Data................................................................. 27

Table 3. Demographic Characteristics by Site ................................................................ 29

Table 4. Comparison of Predictor Variables by Site ........................................................ 30

Table 5. Follow-up Information for Subjects who Relapsed .......................................... 31

Table 6. Demographic Characteristics by Outcome Group .................................................. 33

Table 7. Differences between Relapsers and Abstainers .............................................. 34

Table 8. Intercorrelations among Predictor Variables and Relapse Criterion Variables ............. 35

Table 9. Standard Discriminant Function Analysis of Relapsers and Non-Relapsers..................38

Table 10. Hierarchical Discriminant Function Analysis Examining Experiential Avoidance........ 41

Table 11. Discriminant Function Coefficients and Correlations for Predictors Entered in

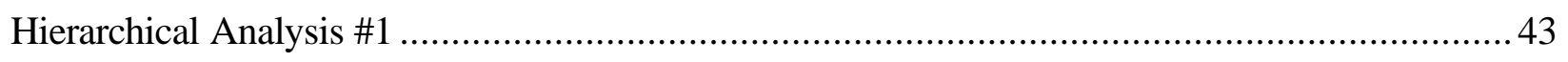

Table 12. Hierarchical Discriminant Function Analysis Examining Interaction between

Experiential Avoidance and Negative Life Events .................................................. 44

Table 13. Discriminant Function Coefficients and Correlations for Predictors Entered in

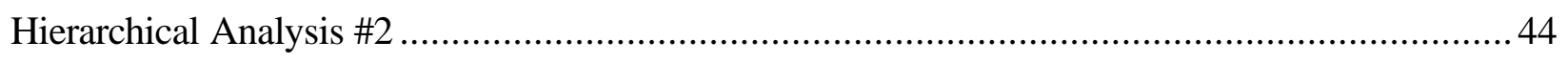

Table 14. Hierarchical Discriminant Function Analysis Examining the BAI and other Strong

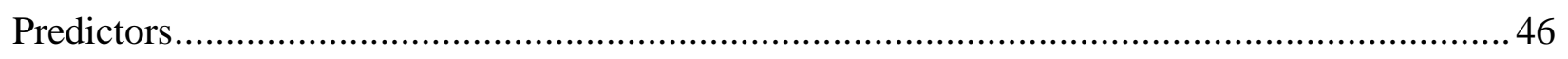

Table 15. Discriminant Function Coefficients and Correlations for Predictors Entered in

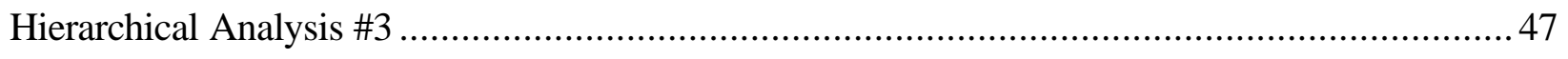




\section{Experiential Avoidance and Alcohol Dependence Relapse}

This project examined the construct "experiential avoidance" in the context of alcohol dependence relapse. Specifically, this study assessed whether experiential avoidance differentiated relapsers from non-relapsers. In addition, two constructs that have been previously related to relapse were examined. These constructs, avoidant coping and stressful life events, may indirectly reflect emotional avoidance and were thus explored in terms of their relation to emotional avoidance and to relapse. This report will provide (a) a brief discussion of experiential avoidance; (b) a review of the literature on negative affect, avoidant coping, and stressful life events as they relate to alcohol dependence relapse; (c) the three hypotheses tested by this project; and (d) the obtained results. Finally, a discussion of the findings and suggestions for future study will conclude this report.

\section{$\underline{\text { Experiential Avoidance }}$}

Experiential avoidance is the phenomenon that occurs when one is unwilling to experience particular internal experiences and attempts to alter them accordingly. "Private experiences" refer to subjective phenomena, such as emotions, thoughts, and bodily sensations (Hayes, Wilson, Gifford, Follette, and Strosahl, 1996). As such, experiential avoidance does not distinguish between private events (i.e., avoidance of emotions vs. avoidance of cognitions), but considers them intermingled. The converse of experiential avoidance, experiential acceptance, refers to one's willingness to experience such phenomena as they are (i.e., without having to do something about it). Hayes et al. add that "avoidance" includes both overt and covert escape behaviors, so long as the intention is to alter one's current experience.

The concept of experiential acceptance/avoidance is not new. Mindful meditation according to Buddhist philosophy means to live with one's experience without evaluation, 
judgment, or doing. The practice of mindfulness is the linchpin of many types of Western relaxation and meditation methods (Beck, 1989, Marlatt, 1994). The importance of experiential avoidance has not gone unrecognized in the field of psychology. Many psychological therapies (i.e., Gestalt, client-centered, existential) have long recognized the deleterious effects of avoidance, whether it be termed repression, denial, or avoidance, and whether it be in response to inner conflicts, dissonant thoughts, or fear of death. However, the issue of avoidance is typically viewed as only one aspect of a larger clinical problem. In contrast, recently developed behavioral therapies such as acceptance and commitment therapy (Hayes \& Wilson, 1993; 1994), and dialectical behavior therapy (Linehan, 1993), have made experiential avoidance/acceptance a central focus. In essence, these modern therapies consider experiential avoidance a common denominator of many psychological disorders, and focus on modifying clients' attempts to control private events (Hayes \& Melancon, 1989, Hayes et al., 1996). The emergence of this emphasis on experiential acceptance represents a significant shift from traditional cognitive and behavioral approaches that have single-mindedly focused on "fixing" a client by changing private experiences (Marlatt, 1994). This development gradually arose from ongoing assessment and evaluation of "what works" (and what doesn't), and adherence to empirically-derived learning principles (see Hayes \& Wilson, 1993, for a review of the behavior-analytic genesis of action and commitment therapy). Several treatment approaches have begun to include techniques geared towards increasing experiential acceptance (e.g., Barlow's work with panic disorder, 1988; Linehans' treatment for borderline personality disorder, 1983). Preliminary outcome data is encouraging, particularly among client populations that have previously resisted therapeutic improvement (Barlow, 1988; Hayes, 1994; Linehan; Marlatt, 1994). 
In theory, experiential avoidance may be particularly relevant to those who are dependent upon alcohol (dependence on other drugs can certainly be included in this concept). By definition, experiential acceptance is precluded if someone is consuming alcohol in order to alter one's inner experience (Marlatt, 1994). As will be shown in the following literature review, there is ample evidence that this is often the case. While experiential avoidance may be an important factor in substance use in general, it may be at the very heart of relapse. Individuals who wish to remain abstinent but relapse instead, have thus engaged in behavior contrary to an identified goal. It is feasible that an intolerance of the internal experiences that occur in the absence of alcohol interferes with remaining abstinent.

\section{Literature Review}

\section{Alcohol Dependence Relapse}

The statement that relapse is a problem in treating alcohol dependence is both obvious and an understatement. Although rates vary, current relapse estimates range from $80 \%$ to $90 \%$, with 50-60\% of alcohol-dependent individuals relapsing within the first three months of treatment (Marlatt, 1985; Mackay \& Marlatt, 1991). Equally obvious are the harmful effects of alcohol abuse and dependence both upon the addicted individual and upon society as a whole. The psychological, physical, financial, and societal costs have been beyond measure (Marlatt \& Gordon, 1980). Accordingly, a massive effort has been put forth to confront this problem. Unfortunately, efforts to understand the alcohol dependence process and to successfully treat dependent individuals have met with only marginal success (Mackay \& Marlatt; Donovan \& Marlatt, 1988).

Although it has not been studied specifically, the literature on alcohol abuse relapse does suggest experiential avoidance may be related. Three particular variables that can be incorporated 
within the experiential avoidance framework have been consistently implicated in alcohol relapse. These variables (a) negative affective states, (b) avoidant coping, and (c) stressful life events, have consistently predicted relapse both independently and in combination with other factors (Cunningham, Sobell, Sobell, Gavin, \& Annis, 1995; Marlatt, 1996; Vuchinich \& Tucker, 1996). Numerous models have been put forth that attempt to coherently link these variables to relapse; these can be separated into two broad categories (Tucker \& Vuchinich, 1992; Vuchinich \& Tucker, 1996). One category is generally derived from cognitive social learning theory, which considers relapse a coping response to a perceived threat. Various models include negative affect, stress levels, negative life events and high-risk situations as constituting the "perceived threat", and coping skills, expectations, and self-efficacy as mediating variables (Annis \& Davis, 1988, Brown et al. 1994; Marlatt \& Gordon, 1985). The second category stems from motivation and classical conditioning theory, and includes models that suggest certain environmental, affective, and biological stimuli that may evoke a conditioned response (i.e., a motivational state or affective response, depending on the model) that then elicits relapse (Childress, McLellan, Natalie, \& O'Brian, 1987; Stasiewicz \& Maisto, 1993). Both categories suggest that an individual's subjective experience, whether a conditioned response or a cognitive/affective state mediated by other variables, is a precipitant of relapse. If this is indeed the case, then logic dictates that increasing one's ability to accept, tolerate, and live with this subjective experience without feeling the need to manage or alter it in some way would be beneficial in maintaining abstinence. Recently, efforts have been made to incorporate the notion of acceptance into substance abuse treatment. Marlatt (1994) now advocates "contingent mindfulness training" in which clients are first taught to recognize the stimuli that trigger an urge, and that such feelings can be borne without ameliorative action. "Urge surfing", as it is called (Marlatt \& Gordon, 1985), refers to 
the use of a wave metaphor to describe how urges, cravings, and other negative emotions naturally increase, crest, and then subside. Another example is the renewed interest in two-factor avoidance theory (Stasiewicz \& Maisto). Cue exposure has historically been used to reduce conditioned responses to alcohol relevant stimuli; unfortunately the effects have not been shown to generalize to the vast number of alcohol-related stimuli outside the laboratory (Childress et al.; Marlatt, 1990). In contrast, two-factor avoidance theory posits that cue exposure should extend beyond extinguishing responses to alcohol-related stimuli to include exposure to the conditioned emotional responses themselves (however it could be argued that the goal of the latter example is to extinguish, rather than accept these conditioned emotional responses). Both of the previous examples illustrate a current focus on experiential acceptance in treatment settings. By contrast, research on experiential avoidance per sé has been limited. As previously discussed, the alcohol relapse literature does consistently reveal negative affect, avoidant coping and the occurrence of environmental stressors as predicting relapse. Operating on the assumption that some individuals resist accepting their current experience because of its negative valence, both negative affect and negative experiences that evoke negative affect may be related to emotional avoidance. Similarly, coping behaviors geared towards controlling or altering inner experiences may also represent emotional avoidance. Before commencing a brief review of the literature, it should be pointed out that these variables only tap a part of this construct and are therefore imperfect indicators of its presence in alcohol relapse.

Negative Affect and Relapse

In 1980, Marlatt and Gordon interviewed 65 male alcohol dependent inpatients who had relapsed following completion of an aversive conditioning program. Over 50\% reported they had relapsed because they had either felt frustrated or angry, or because they felt pressured to drink. 
They conducted a second retrospective study with 70 male alcoholics and found that $37 \%$ had relapsed in response to a negative emotional state, $15 \%$ in order to cope with interpersonal conflict, and 24\% due to social pressure (cited in Marlatt \& Gordon, 1985). The percentage of subjects who endorsed avoidant responses is even greater when the categories proposed by the authors are assessed in terms of whether they represent negative experiences (i.e., negative physical states, urges, interpersonal conflict). When reasons for relapsing are grouped in this way, $70 \%$ could be considered due to negative experiences. Farber, Khavari, \& Douglas (1980) administered a two-part questionnaire (the first section concerning reasons for drinking and the second involving frequency and quantity of alcohol consumption) to 2,496 individuals from differing socioeconomic backgrounds (i.e., military units, college undergraduates, local labor union members, and the general population). Exploratory factor analyses on the reasons for drinking revealed two factors; drinking to alleviate an aversive or undesirable state, and drinking to obtain certain social objectives (e.g., peer acceptance). Additional analyses revealed that individuals who drank to escape unpleasant emotional/physical states demonstrated the highest levels of alcohol consumption. Annis \& Davis (cited in Annis \& Davis, 1988) found similar results in 1984 after conducting a study in which therapists rank-ordered high vs. low-risk drinking situations for alcohol-dependent clients. Negative emotional states represented the highest-risk for $39 \%$ of their clients. When drinking due to negative physical states, urges, and interpersonal conflict was added, these situations comprised the highest-risk for $63 \%$ of their clients. These studies provoked numerous efforts to elucidate the role of negative experiences in relapse.

Because the studies described above were retrospective, a causal relationship between negative affect and relapse would be speculative. The generalizability of the findings was further 
limited by the fact that they relied solely upon subjects' self-reports (corroborative information was not obtained). In addition, there has been some evidence of a mood-congruent memory bias in recall (for a review see Matt, Vazques, \& Campbell, 1992). That is, individuals' current emotional state influences recall, both in terms of what is remembered as well as the memory's affective valence. In order to assess whether mood-congruent memory bias explained the prominence of reported negative affective states in relapse, Hodgins, el-Guebaly, and Armstrong (1985) conducted the following prospective study: Individuals presenting for treatment of alcohol problems were assigned to either (a) a retrospective condition in which they were interviewed initially and at 3,6,9, and 12 months, or (b) a prospective condition in which they provided daily self-monitoring. At six months, the mood ratings from both groups were compared and no significant evidence was found for a negative bias in the retrospective reports. Significantly, the most frequent precipitant of relapse in both groups was negative emotional states (accounting for $53 \%$ of relapses). In a prospective study of 198 individuals formerly treated for alcoholism, Litman, Stapleton, Oppenheim, Peleg, and Jackson (1983) administered questionnaires at six weeks, six months, and twelve months after discharge. Using principal components analyses, the authors found that "unpleasant mood states" accounted for the greatest amount of variance between relapsers and abstainers. Vuchinich and Tucker (1996) also conducted a prospective study of 26 alcoholic men who self-monitored daily alcohol consumption, reasons for drinking, overall mood state, and positive and negative life events. Forty percent of all drinking episodes were attributed to negative internal states (10\% were negative physical states, $22 \%$ were urges, 9\% were interpersonal conflict). Two cross-sectional studies have also supported the role of negative affect in alcohol relapse (Cunningham, Sobell, Sobell, Gavin, \& Annis; 1995; McKirnan \& Peterson, 1988). 
More recently, Cooney, Litt, Morse, Bauer, and Gaupp (1997) conducted a parametric laboratory study exploring alcohol cue reactivity, negative-mood reactivity and relapse in a cohort of men receiving treatment for alcohol dependence. The authors induced negative moods in their subjects via a guided imagery procedure, then exposed them to alcohol or drinking water. Subjects were told to hold and sniff the beverage glass, after which they were instructed to provide self-ratings on mood, desire to drink, and self-efficacy. Both the alcoholic beverage cue and the induced negative mood independently led to increased reported desire to drink. Further, the negative mood combined with alcoholic beverage exposure condition predicted the length of time before relapse after the subjects were discharged from inpatient addiction treatment.

\section{$\underline{\text { Life Events and Relapse }}$}

Although the deleterious sequelae of environmental stressors have been well established (Billings \& Moos, 1982; Brown et al., 1990; Holahan \& Moos, 1987; O’Doherty \& Davies, 1987), the nature of the association between such events and alcohol relapse is not as clear. Attempts to explore this possible relationship further have been impeded by the following difficulties:

1. What constitutes an environmental stressor has been controversial. Many researchers in this area utilize quantitative measures to assess the impact of life events (Billings \& Moos, 1982; Hall \& Havassy, 1990; Moos, Fenn, Billings, \& Moos, 1989; Mulford, 1983). Researchers disagree as to whether or not positive life events should be included, some feeling that positive events are still "stressful" as they necessitate an adaptive response (Brown, Vik, Patterson, Grant, \& Schuckit, 1994). Others feel negative events alone are relevant to relapse (Hall \& Havassy; Cooper, Russel, Skinner, Frone, \& Mudar, 1992). Other researchers prefer to explore (either in place of, or in addition to the actual frequency of life events) perceived stress (Brown et. al; Rosenberg, 1983; 
Vuchinich \& Tucker, 1996). This is in recognition that an event considered negative by one individual may not be perceived so by another. Finally, what some researchers consider to be responses to stress (e.g., mood, physical symptoms), others consider to be stressors themselves (Brown et al.; Hall \& Havassy).

2. The way in which life events are assessed can significantly affect subsequent findings. For example, some researchers have argued that the effects of environmental stressors upon relapse are not revealed by simple, frequency counts. Rather, the stressors' duration, whether they are acute or more chronic, whether they occurred pre- or posttreatment, and whether they are alcohol-related (i.e., a suspended drivers' license, loss of a job) are pertinent aspects that influence their subsequent impact on relapse. Brown et al. (1990) found that highly threatening stressors and severe ongoing difficulties predicted relapse, whereas the total number of stressors both preand posttreatment did not. However, as noted by Dohrenwend, Dohrenwend, Dodson, \& Shrout (1984), measuring such effects of life events confounds the outcome with the stressor.

3. The relationship between stress and relapse is complex in that it is bi-directional (i.e., relapse itself can become a stressor) and is mediated by other factors, such as one's response to stress, access to alternative reinforcers, and social support (Brown et al., 1994; Cooper et al, 1992; Hall, Havassy \& Wasserman, 1990; Litman, Eiser, Rawson, \& Oppenheim, 1983; McKirnan \& Peterson, 1988; Tucker \& Vuchinich, 1992; Vuchinich and Tucker, 1996).

The difficulties described above help explain the inconsistent results found in empirical studies of the stress-relapse relationship. The majority of research in this area has shown positive correlations between negative events and relapse (Litman, Eiser, Rawson, \& Oppenheim, 1983; Litman, et. al., 1983; McKirnan \& Peterson, 1988; Cronkite \& Moos, 1980; Rosenberg, 1983; Vuchinich \& Tucker, 1996). Others show no direct effects (Horé, 1971; Mulford, 1983). In 
addition to the complications listed above, a possible explanation for the equivocal results is the frequent use of non-standardized measures that makes replication and extension efforts difficult. Another explanation is that the majority of these studies rely upon retrospective data. Hall, Havassy and Wasserman (1990) showed that data taken prospectively showed no significant relationship between stress (defined as hassles and negative mood), whereas retrospective data showed a significant association. However, Breslin, O’Keefe, Burrell, Ratliff-Crain, and Baum (1995) and Vuchinich and Tucker (1996) demonstrated that stress was related to drinking by utilizing daily diaries as measures of perceived stress, mood and alcohol consumption.

Several other researchers have also proposed that stressful events interact with other variables to influence the probability of alcohol relapse (Annis \& Davis, 1988; Hall, Havassy, \& Wasserman, 1990; Marlatt \& Gordon, 1985). For example, Billings and Moos (1983) conceptualized subjects' social resources and coping responses as "stress-mediating factors", and considered the balance between these factors and stressful events as crucial to recovery from alcoholism. Drawing from a longitudinal study of 113 patients who had received inpatient treatment for alcohol and their families, the authors identified 58 relapsed subjects and 55 "recovered" subjects. (The latter was defined as individuals who had no alcohol-related problems or hospitalizations and who consumed less than five ounces of $100 \%$ ethanol on any given day at both six-month and two-year follow-up intervals. Thirteen of the 55 "recovered" subjects indicated they had engaged in some moderate drinking.) A closely matched community comparison group was then formed, and data was obtained on the occurrence of stressful life events, coping responses, and several indices of outcome functioning (such as alcohol consumption, anxiety, and depression). Negative life events were found to be twice as prevalent in the relapsed group of subjects, and these individuals reported experiencing approximately half 
as many positive events than the recovered subjects or controls. In addition, the relapsed subjects used significantly more avoidance coping responses (e. g., trying not to think about the problem) than did the other two groups, and used significantly less active cognitive and behavioral responses (such as taking some action, considering alternatives, etc.). Recovered subjects reported similar levels of social resources to controls, while relapsed subjects reported less positive family, work, and informal social networks.

Cooper, Russell, Skinner, Frone, \& Mudar (1992) examined the relative power of stressors (defined as stressful events that occurred in the past year and their rated impact), coping, expectancy, and gender to predict relapse. Stressors independently only accounted for $<2 \%$ of additional variance. However, when the interaction between stress and coping, expectancies, and gender were entered into the equation predictive power was significantly increased.

This synopsis of the literature on the relation between life events and relapse to alcohol dependence illustrates that this association is variable, difficult to study and harder to interpret. Nonetheless, the majority of the work in this area indicates that at least a moderate association exists. Given the persistent presence of negative affect as a precipitant of relapse, the occurrence of life events must be included in any examination of the relapse process.

\section{Coping and Relapse}

The previous sections have conceptualized the act of relapsing as a compensatory response to a stressor. Relapse to drinking is thus viewed as a way to "cope" with negative internal experiences and external stressors. However, a large body of research views coping as a mediating variable between a stressor and subsequent relapse. This view posits that the actual occurrence of negative events may be less important than how an individual copes with these events (Aldwin \& Revenson, 1987). "Coping" is defined as "constantly changing cognitive and 
behavioral efforts to manage specific external and/or internal demands that are appraised as taxing or exceeding the resources of the person" (Lazarus \& Folkman, 1984, p.141). The notion that the stressor is perceived as negative or a threat is important (otherwise any behavioral response could be called 'coping"), as is the idea that a second mediating variable, appraisal, interacts with the coping response. A common feature of coping and relapse research is that variables such as appraisal (Cooper et al., 1992; Meyers \& Brown, 1990a, 1990b; Marlatt \& Gordon, 1985), expectancies (Annis \& David, 1988; Cooper, Russell, \& George 1988), and self-efficacy (Brown et al., 1994; Litman, Eiser, Rawson, \& Oppenheim, 1979; Marlatt \& Gordon, 1985) are thought to influence which coping strategy an individual selects in a given situation. Before presenting the work relevant to the present project, it is important to point out some of the conceptual difficulties in this area of research.

1. Numerous attempts, both theoretically and empirically based, have been made to differentiate types of coping, or coping strategies. The result is a bewildering array of coping measures. Empirically based coping taxonomies have been derived from factor analytic procedures conducted on various population samples. The reliability of the derived factors has been problematic (Schwarzer \& Schwarzer, 1993). For example, the most commonly used coping measure, the Ways of Coping Checklist developed by Folkman \& Lazarus (1980), produces extracted factors that can differ according to the sample or nature of assessed stressor (Aldwin \& Revenson, 1987; Schwarzer \& Schwarzer, 1993; Vitaliano, Russo, Carr, Maiuro, \& Becker, 1985). In addition, the numerous emergent factors have interrelationships that are often overlooked. For example, "seeking social support" can also involve other defined strategies, such as seeking information, problem solving, and distracting oneself (Folkman \& Lazarus, 1980; Schwarzer \& Schwarzer (1993). Similarly, theoretically based categories engender their own 
difficulties. To demonstrate; Neidigh, Gesten, \& Shiffman (1988) separated coping strategies from other measures into either cognitive or behavioral domains in order to compare their effectiveness in coping with temptations to drink. This is not a meaningful classification as it is impossible to partial out the cognitive component from a behavioral action. For example, the "behavioral" coping responses, to "refuse drink", or to "relax", no doubt occurred with an accompanying thought process. Not surprisingly, authors who have attempted to distinguish behavioral from cognitive coping have not reported significant differences between approaches in terms of how well they predicted relapse (Meyers \& Brown, 1990a; Moser \& Annis, 1996; Neidigh, Gesten, \& Shiffman, 1988).

2. The problem described above is echoed in efforts to examine constructs such as "expectancies" and "appraisal" and their relation to coping. As stated by Schwarzer \& Schwarzer (p. 107, 1993) “....appraising a situation as a threat may trigger coping (further thoughts or defenses that imply a reappraisal of the same situation as being more or less threatening)." In this sense, appraisal and overt coping actions are entangled, as are overt coping actions and constructs such as efficacy, or expectancies.

3. Differentiating between types of coping strategies obfuscates the fact that coping is a process. That is, more than one strategy is typically used in a stressful situation. Whether a given approach is linked to features of the stressor (e.g., degree of threat) or to temporal factors (the first vs. second strategy called upon) is unclear at this time (Lazarus, 1993).

4. Coping strategies differ in how consistent or stable they are across time. Some appear to be more stable than others, but many change from one situation to another. There is some evidence that some dimensions might be more stable, such as "positive reappraisal", while others, such as 
“seeking social support" depend more upon a given context (Lazarus, 1993; Schwarzer \& Schwarzer, 1993).

The fact that the interest in coping persists despite the above-mentioned difficulties is evidence that some heuristic value to the construct remains. While lacking the descriptive power of more finely grained coping categories, broader categories of coping have been found to differentiate between individuals who abstain from drinking posttreatment and those who relapse. For example, positive or problem-focused coping styles (i.e., attempts to change the situation by direct action) have been related to abstinence (Cronkite \& Moos, 1980; Meyers \& Brown, 1990b), and passive or avoidant coping (i.e., physiological or psychological withdrawal from the situation) has been associated with relapse (Brown et al., 1994; Cooper et al, 1992). The previously described study by Billings and Moos (1983) determined that alcoholic patients who relapsed used significantly more avoidant coping responses than patients who had not relapsed, and also that negative life events had less deleterious effects on patients who utilized problemfocused coping. In a cross-sectional design of 199 randomly drawn adults, Cooper, Russell and George (1988) conducted interviews assessing alcohol consumption, reported drinking to cope, positive alcohol expectancies, and general coping skills. A path analysis revealed that drinking to cope was the most powerful explanatory variable in problem drinking. The authors state that avoidance coping and anger suppression were also significant variables, but only when interacting with positive expectancies. Because drinking to cope (an avoidant coping strategy) was separated in the analysis from general coping styles, these findings are difficult to interpret. However, similar findings were reported in a second cross-sectional study (Cooper et al., 1992) that showed avoidance coping was significantly related to heavy drinking and alcohol-related problems. In a 10-year longitudinal study, Moos (1992) determined that both 2-year and 10-year treatment 
outcomes were significantly better for those individuals who relied less heavily on avoidance coping strategies.

Brown et al. (1994) conducted a prospective study to assess whether the effects of acute or chronic environmental stressors would interact with "psychological vulnerability" (defined as the interaction between protective and risk factors) to predict relapse. An individual's repertoire of coping skills was considered a protective factor. Psychological vulnerability was found to significantly predict relapse at a one-year follow-up, but not at three months. The number of coping responses predicted relapse, with individuals displaying more coping strategies being less likely to relapse. Unfortunately, the authors do not differentiate between types of coping (emotion-focused v. problem-focused). Litman, Eiser, Rawson, \& Oppenheim (1979), Meyers \& Brown (1990a, 1990b), and Moser \& Annis (1996) also found that that multiple and flexible coping styles protect against relapse.

The lack of agreement regarding the classification of coping responses and the surprising frequency with which researchers use idiosyncratic coping measures obscures interpretation of the literature. The presence of avoidant coping as a predictor of alcohol-related problems and relapse is pertinent to the present discussion however, and has appeared persistently enough in the literature to warrant further consideration.

\section{Demographics and Relapse}

A substantial body of research has been conducted examining various demographic features and relapse to alcohol dependence. Because it is important to consider the importance of these features when examining relapse, a synopsis of this body of work is offered here.

In essence, the findings depend largely upon the population studied. Studies of ethnicity and relapse to alcohol dependence generally suggest that minorities are more likely to relapse, but 
these findings are confounded by socioeconomic status, a demographic variable consistently shown to increase risk of relapse (Caetano \& Shafer, 1996; Ellis \& McClure, 1992). For example, recent research has shown that less affluent Black men are more likely to relapse than less affluent White men, but affluent Black men were less likely to relapse than affluent White men (Jones-Webb, Hsiao, Hannan, 1995). Males appear at greater risk of both alcohol severity and relapse than females, although recent trends indicate the distance between genders is closing (Ellis \& McClure, 1992; Rubin, Stout, and Longabaugh, 1996). In fact, a recent study by Annis, Sklar, \& Moser (1998) of 90 male and 38 female subjects with alcohol dependence revealed no gender differences in relapse rates three months after receiving addiction treatment. Younger alcoholdependent individuals are less likely to complete treatment programs and more likely to relapse after treatment than older individuals (Booth, Blow, Cook, Bunn, and Forney, 1992).

This literature review was not exhaustive. Rather than including all the research on alcohol dependence, it has focused on relapse, and in particular, three factors that are thought to influence the relapse process. When considered in total, the results suggest that negative affect, life events, and avoidant coping are related to each other and to alcohol dependence relapse. That is, negative affect occurs in the context of negative life events, and avoidant coping (i.e. alcohol consumption) is a common but maladaptive means to ameliorate these unpleasant experiences. This dynamic can also be said to represent experiential avoidance. Accordingly, the hypothesis that experiential avoidance is related to alcohol dependence relapse does not seem a theoretical stretch.

\section{Purpose}

The following study explored the role of experiential avoidance in alcohol dependence relapse. A new measure of experiential avoidance and acceptance, the Acceptance and Action 
Questionnaire (AAQ), was used to assess whether experiential avoidance differentiated individuals who relapsed after inpatient treatment for alcohol dependence, from those who remained abstinent. In addition, two other measures thought to reflect the presence of experiential avoidance were also used to distinguish relapsers from non-relapsers. These measures were an avoidant coping measure, and a measure of negative life events. The convergent validity of the AAQ was therefore also explored in terms of its association with avoidant coping and negative life events. Discriminant function analyses were used to test the following specific hypotheses:

1. The AAQ will significantly differentiate alcohol-dependent relapsers from non-relapsers.

2. Relapsers will be significantly more likely to engage in avoidant coping than non-relapsers.

3. Relapsers will endorse significantly more negative life events than will non-relapsers.

Method

\section{$\underline{\text { Subjects }}$}

All subjects who participated in this study did so on a voluntary basis and signed a consent form that included their rights as research subjects. Most all the individuals approached for participation agreed to be subjects; approximately five individuals refused. All subjects' data remained confidential and was coded by number. Identifying information was used only for follow-up purposes, and was then destroyed when this final phase was completed.

Eighty-five adult subjects were drawn from two adult substance abuse treatment facilities. Preston Addiction Treatment Center is a hospital-based detoxification and rehabilitation facility. Chestnut Ridge Addiction Recovery Unit is a freestanding psychiatric facility that provides both inpatient and intensive outpatient substance abuse treatment programs. To reduce discrepancies between subjects from each site, participants were drawn only from the inpatient unit at Chestnut 
Ridge. Inclusion criteria were (a) primary diagnosis of alcohol dependence, (b) availability of a resource person (i.e., a significant other who could provide corroborative information and who would serve as a secondary contact), and (c) a reported abstinence goal. Exclusionary criteria were (a) individuals who were actively psychotic or demented, and (b) individuals who remained in treatment for less than five days. Subjects were administered questionnaire packets at their respective treatment facility, within the first two weeks of treatment. Individuals were not administered questionnaires while undergoing detoxification.

Measures

Alcohol Dependence. The Self-Administered Alcoholism Screening Test (SAAST) is a 34-item self-report measure designed to identify individuals with alcohol dependence (Swenson \& Morse, 1975). This questionnaire was originally derived from the Michigan Alcoholism Screening Test (MAST), a measure of demonstrated clinical value. The developers of the SAAST modified the MAST so that the test could be self-administered. Thirty-four non-weighted items are presented in a simple Yes-No format. A score of 7 or greater (out of 34 possible) distinguishes alcoholics from non-alcoholics. This measure was selected primarily because it was already in use at one of the treatment settings from which subjects in this study were drawn. In addition, the SAAST is easy to use, and has been shown to have good reliability and sensitivity. For example, Hurt, Morse, \& Swenson (1980) administered the SAAST to 1,002 patients in a general medical population, testing the ability of the SAAS to identify those patients with possible or probable alcoholism. Comparing test scores with patients' medical records, the authors reported a falsenegative rate of $6.7 \%$. Using a sample of 1156 medical patients, Davis, Hurt, Morse, \& O’Brien (1987) conducted a discriminant analysis of the SAAST's ability to identify alcoholic patients. The test was able to correctly classify $96.4 \%$ of individuals correctly. A cross-validation effort 
resulted in only one additional misclassification. Davis and Morse (1987) demonstrated concurrent validity between the SAAST and spouses' reports of problem drinking. The measure has also been shown to be sensitive to moderate drinkers that can be overlooked by other measures (Swenson \& Morse, 1975).

Life Events. The Life Experiences Survey (LES) was developed by Sarason, Johnson, and Seigal (1978) to assess the occurrence of life events. Respondents indicate which events they have experienced during the last year (for the purposes of this study, they were asked to indicate what occurred in the prior three months), and rate whether the event had a positive or negative impact (-3 being "extremely negative", +3 "being extremely positive"). Items include such events as getting a new job, major change in financial status, divorce, and receiving serious injury. From this two subscales are obtained: The LES-negative is a total of negatively perceived life events, and the positively perceived life events comprise the LES-positive scale. The psychometrics of the LES have not been well established, although there is some evidence of the measure's reliability and validity. For example, a test-retest reliability effort using 34 college undergraduates revealed reliability estimates ranging from $.19(p<.001)$ for the positive scale, to $.56(p<.001)$ for the scale of negative life events. A second study using a larger sample of 58 undergraduates demonstrated the reliability of these scales to be .53 to $.88(p<.001)$ respectively (Sarason, Johnson, \& Siegal, 1978). Convergent validity was somewhat demonstrated in a study comparing LES scores from students seeking assistance at a university counseling center with a control group. The counseling students displayed significantly higher scores on the negative life events scale than did the controls. However, the selection of this measure had more to do with its appropriateness to the present project. That is, it was selected over others that simply provide frequency counts (e.g., the Social Readjustment Scale), as research has indicated that the quality 
of these events (i.e., their positive v. negative valence) has greater influence upon subsequent relapse in alcohol abusers than does the number of events that occurred (Rosenberg, 1983). It was also selected over measures that assess the enduring effects of such events, because these measures confound subjects' responses to stressful events with the events themselves. The LES does not assess the enduring effects of such events, nor how they were responded to, merely whether they were perceived as negative, or positive occurrences at the time the event occurred. Experiential Avoidance. The Acceptance and Action Questionnaire (AAQ) is a 32-item measure designed to assess emotional acceptance and emotional avoidance (Hayes, Strosahl, \& Wilson, in press). Although largely under development at this time, the developers of the AAQ reported a confirmatory factor analysis revealed a 16-item, single factor solution that was crossvalidated in a second large-scale study (Hayes et al.). The refined 16-item AAQ has respondents rate (on a scale of 1 , "never true", to 7 , "always true") the degree to which statements apply to them. High scores are indicative of experiential avoidance and immobility, low scores are indicative of acceptance and action. This scale has also been shown to correlate significantly with measures of depression and anxiety (e.g., .66 with the Beck Depression Inventory, .40 Beck Anxiety Inventory), and to accurately discriminate between the clinical cutoff scores for both scales (Hayes et al.).

Coping. The Coping_Strategy_Indicator (CSI) is a situation-specific coping measure consisting of 33 coping options (Amirkhan, 1990). Subjects indicate to what degree (i.e., "a lot", "a little", or "not at all") they endorse different coping responses to an identified stressor. The measure was first rationally, then empirically derived. That is, the developer collected various coping behaviors from previous research and from existing measures, then conducted a series of factor analysis with independent large samples. This procedure resulted in three coping subscales. 
The three scales, avoidance (hereafter termed CSI-avoidance), problem solving (CSI-problem solving), and seeking support (CSI-seeking support) were further supported by confirmatory factor analyses (Amirkhan, 1990). CSI-avoidance items, such as “daydreamed about better times", and "avoided being with people in general" represent withdrawal from the stressor. Items that comprise CSI-problem solving involve manipulation of the stressor, such as "set some goals for yourself to deal with the situation."'” The CSI-seeking support items include strategies such as "went to a friend to help you feel better about the problem."

Criterion-related validity of the CSI was demonstrated in a series of three studies, the last of which is most pertinent to the present project. Subjects entering a substance abuse treatment program scored more highly on CSI-avoidance than normative means, and lower on CSI-problem solving. When the subjects were re-tested after receiving therapy, these findings were reversed (Amirkhan, 1994; Clark, Bormann, Cropanzano, and James, 1995). The CSI was selected over other measures (e.g., the Ways of Coping-Revised) due to the reliability of its factor structure, and because the three scales (particularly the CSI-avoidant and CSI problem solving) lent themselves particularly well to the hypotheses posed in the present project.

Additional Measures. The Beck Anxiety Inventory (BAI) and Beck Depression Inventory (BDI) were included to assess general psychiatric features of this population (Beck \& Steer, 1993a, 1993b). Both are well-established measures. The BAI assesses severity of anxiety, and consists of 21 items that are rated on a 4-point scale ranging from 0-3. Individuals who score 1625 are considered moderately anxious, and those scoring 26 or higher are considered severely anxious. The BDI is a widely used measure of depression severity and is comprised of 21 items that reflect depressive symptoms and attitudes. These items are rated on a 4-point scale ranging 
from 0-3 in terms of severity. Scores of 17 to 29 are considered indicative of moderate depression, and scores of 30 or higher indicate severe depression.

\section{Design and Procedure}

Chestnut Ridge Addiction Recovery Unit. As patients were admitted to the previous medical and psychosocial information was gathered by staff as part of a standard intake procedure. Active psychosis and dementia was assessed as part of a standard intake/treatment planning procedure. Once appropriate (as detailed in the inclusion and exclusion criteria) individuals were solicited for participation and provided instructions for the study. The first phase occurred at the treatment facility, where amenable subjects were given packets containing a demographic information sheet, the SAAST, AAQ, CSI, BAI, and BDI. The questionnaires took 30 to 60 minutes to complete. Approximately three months from the date of their discharge, subjects were contacted by phone to complete a brief phone interview to assess for relapse and the occurrence of life events via the LES. These interviews ranged in duration from 15 to 30 minutes. Each subject was asked whether he or she had consumed any alcohol in the previous three months. If the subject answered in the affirmative, questions were asked as to the frequency and volume of drinking that had occurred. These subjects were also asked whether they had experienced alcohol-related problems such as DUI's, marital problems, etc. All subjects were asked if they had participated in some form of aftercare, such as AA meetings, and whether they had found this helpful. Finally, each subject's secondary source person was contacted to provide corroborative information. Without being provided any information regarding subjects' responses, these individuals were asked to report whether or not the subject in question had relapsed, and if so, to what degree (i.e., a slip vs. a relapse), and when. 
Preston Addiction Treatment Center. Previous medical and psychosocial information was gathered by staff as part of a standard intake procedure. Assessment for the presence of psychosis was part of a standard diagnostic summary procedure that must occur within seven days of admission. Inter-clinician agreement was also required by at least two of three individuals from differing disciplines (i.e., a nurse, counselor, and physician). Once patients completed detoxification, they were solicited to participate in this study while completing standard paperwork pertinent to their treatment. If appropriate, willing subjects were given the same questionnaire packet previously described. Follow up information was procured in the same manner as well. The subjects' secondary source persons were interviewed in the manner detailed above.

\section{Results}

A total of 85 surveys were administered. As presented in Table 1, eight subjects were lost to follow-up (one deceased), meaning that neither the subjects nor their designated contact persons could be reached. Although it is likely the majority of these individuals relapsed, these cases were dropped from the study as a conservative measure. Five more cases were removed when perusal of their questionnaires revealed these subjects did not endorse total abstinence from alcohol as their goal. One case was dropped due to an extremely low SAAST score (a score of 2, which is well below the cutoff of 7 on this alcohol severity measure). Fifty-nine of the remaining 71 cases were completed and corroborated at follow-up, meaning that subjects' reports were verified by their previously designated contact persons. Although the impetus for obtaining corroborative information arose from a concern that not all subjects would admit to having relapsed, the non-corroborated data from the remaining twelve subjects were included in the analyses. This was because the obtained information suggested that individuals who relapsed 
Table 1

Sample Size, Attrition, and Relapse Information by Site

Chestnut Ridge Preston

Initial Assessment

59

26

Lost to Follow-up

5

3

Did Not Endorse Abstinence

Below SAAST Threshold

4

1

1

0

Remaining Subjects

49

22

Completed and Validated

Completed by Subject Only

41

18

2

6

1

Validated Only

25

$24(49 \%)$

3

Number Abstained

Number Relapsed

$24(49 \%)$

49

13

$9(41 \%)$ 
were accurately reporting or were being accurately reported. For example, three of these cases were non-corroborated because the subjects' contact persons were unreachable. Of these three, two subjects self-reported as having relapsed. The remaining nine cases were completed only by designated contact persons, as the subjects themselves were unreachable. Of these nine subjects, seven were reported by the contact persons as having relapsed. (There were only three cases in which subjects' reports were inconsistent with the reports given by secondary sources. One subject reported a minor lapse despite the fact that the contact person reported nearly continuous drinking. Two situations involved the opposite dynamic, wherein the subjects reported relapsing unbeknownst to the secondary contract persons.) Again, as the chief concern was whether or not relapsers were correctly identified as such, it was determined that the twelve non-corroborated studies could safely be included in the final analyses, resulting in a total sample of 71. Relapse rates were $49 \%$ at Chestnut Ridge and $41 \%$ at Preston, a non-significant difference when compared by a chi-square analysis $\left(\mathrm{X}^{2}(1)=.398, p=.527\right)$

The raw data was then examined (i.e., means, standard deviations, frequency counts, distributions) for outliers and missing values. Two outliers, both more than three standard deviations from the mean score, were transformed according to a procedure described by Tabachnick and Fidell (1996). One outlier was obtained from a subject who reported on his intake as having previously completed 30 inpatient treatment programs (the mean being 2.36 previous programs). As suggested by Tabachnick and Fidell, this value of 30 was transformed to 20, placing it one unit above the next highest obtained score of 19. A similar procedure was used to transform an outlier on the measure of positively perceived Life events (LES-positive). This subject reported a total score of 37 on this measure, more than three standard deviations from the 
mean of 13.18. This score was transformed to 27, placing it one unit above the second highest score of 26.

A second issue concerned missing values. Unfortunately, a fair number were missing, such that subsequent multivariate tests were seriously impacted. An imputation procedure was therefore implemented, effectively replacing many of the missing values (Table 2 displays the 58 randomly dispersed values). As discussed by Tabachnick and Fidell (1996), the imputation procedure constructs a regression equation in which a variable with a missing value becomes the "dependent variable" and other variables serve as independent variables (cases with complete data produce the regression equation). A liability of this method is reduced variance due to the probability that the predicted values may be too close to the mean. However, this method is considered more accurate than simply inserting a mean score for that variable, and given the potential loss of data due to missing values, it was determined that this procedure was appropriate. However, it was also the case that a number of the missing values were non-random. For example, 27 of the 71 subjects did not report income data. This disproportionate number suggests the presence of a particular response style (e.g., cultural beliefs, distrust, embarrassment) rather than random missing values. In addition, two extreme outliers (salaries of $\$ 150,000$ and $\$ 60,000$ compared with the median salary of $\$ 17,250)$ further clouded interpretation. For these reasons "income" was not included in the imputation procedure or in subsequent statistical analyses. And finally, non-random missing values occurred for the follow-up measures of stressful life events. That is, subjects who were unavailable for follow-up, and who were determined to have relapsed or abstained via their contact persons, did not complete the follow-up measure for stressful life events that had occurred during the three months following treatment. For this reason, LES values for these nine scores were not imputed. In sum, 71 cases were included in all 
Table 2

Variables with Imputed Data

\begin{tabular}{|c|c|c|}
\hline Variable & Number of Missing Values & Total with Imputation \\
\hline Education & 7 & 71 \\
\hline Race & 3 & 71 \\
\hline No. Previous Treatment & 1 & 71 \\
\hline SAAST Total $^{\mathrm{a}}$ & 4 & 71 \\
\hline AAQ Total ${ }^{\mathrm{a}}$ & 3 & 71 \\
\hline BDI Total ${ }^{\mathrm{a}}$ & 6 & 71 \\
\hline CSI-problem solving & 1 & 71 \\
\hline
\end{tabular}

Note. Does not include variables missing follow-up data as explained in text (i.e., LES scores).

${ }^{a}$ Missing data regarding the measure total is due to subjects completing all but one skipped, or missed item. 
statistical analyses, with the exception of the multivariate analyses that were conducted on 62 cases.

The data gathered from each inpatient treatment site were compared on all variables. As can be seen in Tables 3 and 4, subjects from the two sites were compared with t-tests and differed on only one variable, the social support scale of the CSI. Subjects at Preston Addiction Treatment Center were significantly more likely to cope with a stressor by seeking social support $($ mean $=25.3)$ then were subjects drawn from the Chestnut Ridge Recovery Unit (mean $=22.0, p$ $=.006)$. There was also a trend $(p=.051)$ for subjects at the Chestnut Ridge Recovery Unit to have received more formal education than subjects at Preston Addiction Treatment Center (means of 12.6 and 11.8 respectively). Because the two groups did not significantly differ in terms of relapse or on the variables of interest, the two samples were accordingly pooled.

\section{$\underline{\text { Subject Classification }}$}

Three months after being discharged from an inpatient alcohol treatment program, 33 individuals (46\%) had relapsed and $38(53 \%)$ had remained abstinent. Along with assessing whether or not abstinence was achieved (i.e., whether any alcohol was consumed), an effort was made to distinguish "slips", defined as less than four drinks during any one episode, from more significant lapses. Only two of the 33 relapsers experienced such slips, and the small group size prohibited further analysis of this variable.

Table 5 presents relapse information for the subjects who reported having relapsed (only the time of relapse was obtained for the seven relapsers who were solely identified by their contact persons). Forty-six percent of the relapsed subjects reported having consumed alcohol within the first month following discharge. Thirty percent relapsed in the second month, and $12 \%$ relapsed in the third month (four subjects were unsure of when they relapsed). No significant 
Table 3

Demographic Characteristics by Site

\begin{tabular}{|c|c|c|c|c|}
\hline & Chestnut Ridge & Preston & & \\
\hline & $\underline{\mathrm{N}}$ & $\underline{\mathrm{N}}$ & $X^{2}$ & $p$ \\
\hline \multicolumn{5}{|l|}{ Gender } \\
\hline Male & 32 & 12 & .75 & .435 \\
\hline Female & 17 & 10 & & \\
\hline \multicolumn{5}{|l|}{ Ethnicity } \\
\hline White & 41 & 20 & .99 & .483 \\
\hline Minority & 8 & 2 & & \\
\hline \multicolumn{5}{|l|}{ Marital Status } \\
\hline Currently Married & 24 & 9 & .40 & .611 \\
\hline Currently Single & 24 & 13 & & \\
\hline \multicolumn{5}{|l|}{ Employment } \\
\hline Currently Employed & 26 & 11 & .56 & .321 \\
\hline Currently Unemployed & 19 & 5 & & \\
\hline
\end{tabular}


Table 4

Comparison of Predictor Variables by Site

\begin{tabular}{|c|c|c|c|c|c|c|c|c|}
\hline \multirow[b]{2}{*}{ Predictors } & \multicolumn{3}{|c|}{ Chestnut Ridge } & \multicolumn{3}{|c|}{ Preston } & \multirow[b]{2}{*}{$\underline{t}$} & \multirow[b]{2}{*}{$\underline{p}$} \\
\hline & $\underline{\mathrm{M}}$ & $\underline{\mathrm{SD}}$ & $\underline{\mathrm{n}}$ & $\underline{\mathrm{M}}$ & $\underline{\mathrm{SD}}$ & $\underline{\mathrm{n}}$ & & \\
\hline Age & 40.6 & $(14.3)$ & 49 & 37.0 & $(7.2)$ & 22 & 1.44 & .153 \\
\hline Education & 12.4 & $(2.2)$ & 49 & 11.7 & $(1.0)$ & 22 & 1.98 & .051 \\
\hline No. Previous Tx. & 2.5 & $(4.5)$ & 49 & 1.0 & $(2.5)$ & 22 & 1.26 & .212 \\
\hline SAAST Total & 22.5 & $(6.2)$ & 49 & 20.8 & $(5.7)$ & 22 & 1.10 & .275 \\
\hline AAQ Total & 74.1 & $(13.7)$ & 49 & 77.6 & $(12.1)$ & 22 & -1.04 & .304 \\
\hline BAI Total & 21.8 & $(16.0)$ & 49 & 26.00 & ( 9.0) & 22 & -1.42 & .160 \\
\hline BDI Total & 17.9 & $(11.5)$ & 49 & 18.8 & $(8.6)$ & 22 & -.351 & .727 \\
\hline CSI-ps & 24.1 & $(6.1)$ & 49 & 26.4 & $(4.9)$ & 22 & -1.57 & .121 \\
\hline CSI-ss & 22.0 & $(6.2)$ & 49 & 25.3 & $(3.5)$ & 22 & -.286 & $.006^{*}$ \\
\hline CSI-av & 22.7 & $(6.1)$ & 49 & 21.0 & $(4.1)$ & 22 & 1.54 & .129 \\
\hline LES-neg & 6.6 & $(7.8)$ & 43 & 7.0 & $(8.1)$ & 19 & -.149 & .882 \\
\hline LES-pos & 11.8 & ( 6.3) & 43 & 15.9 & $(9.0)$ & 19 & -1.80 & .083 \\
\hline LES-total & 10.7 & $(8.9)$ & 43 & 12.6 & $(10.2)$ & 19 & -.723 & .473 \\
\hline
\end{tabular}




\section{Table 5}

Follow-up Information for Subjects who Relapsed

\begin{tabular}{cr}
\hline & No. of Relapsers $(\%)$ \\
\hline Follow-up Questions & \\
Time of Initial Relapse & $15(45.5)$ \\
First Month & $10(30.3)$ \\
Second Month & $4(12.1)$ \\
Third Month & $4(12.1)$ \\
Unsure & \\
Severity of Relapse & $2(6.1)$ \\
Slip (<4 drinks) & $31(93.1)$ \\
Relapse $(\geq 4$ drinks) & \\
Became Intoxicated & $7(21.2)$ \\
No & $19(57.6)$ \\
Yes & $7(21.2)$ \\
Missing & \\
Experienced Blackout & $17(51.5)$ \\
No & $9(27.3)$ \\
Yes & $7(21.2)$ \\
Missing & \\
& \\
\hline
\end{tabular}


correlation was found between time of relapse and subjects' scores on the initial assessment measures. Nineteen subjects who relapsed reported becoming intoxicated (nine to the point of having a blackout), whereas seven individuals who relapsed denied becoming intoxicated. Subjects reported a variety of reasons for relapsing, ranging from boredom to a familial argument. Although ten subjects responded that they did not know why they relapsed, 22 of the remaining 23 relapsers attributed their relapse to a negative internal state. The exception was one subject who reported she relapsed to celebrate a recent promotion, but it could be argued, given her declared abstinence objective, that she was unwilling to experience what refraining from celebrating in this manner would entail (e.g., diminished pleasure, longing for alcohol).

As illustrated in Tables 6 and 7, comparison of group means revealed that relapsers and non-relapsers were comparable in terms of sociodemographic features and pretreatment alcohol use. Chi-square analyses revealed no statistically significant differences between relapsers and non-relapsers in terms of gender, ethnicity, or marital status. In addition, $t$ tests of group mean differences in education, SAAST scores, and number of previous treatment programs were also non-significant. There were significant group differences however, on three variables. Relapsers were significantly older $(t=2.14, p=.036)$ than were non-relapsers (means of 36.2 and 42.4 respectively), endorsed significantly more anxiety symptoms on the BAI $(t=-2.99, p=.004$, means of 28.66 for relapsers vs. 18.5 for non-relapsers), and reported having experienced significantly more negative events after discharge $(t=-2.71, p=.010)$ than did non-relapsers (means of 10.02 and 4.36 respectively).

\section{$\underline{\text { Simple Correlations }}$}

The correlation matrix presented in Table 8 shows low to moderate correlations (ranging from $r=-.23$ to $r=.61$ ) between predictor variables. The BAI was shown to be broadly 
Table 6

Demographic Characteristics by Outcome Group

\begin{tabular}{|c|c|c|c|c|}
\hline & Relapsers & Non-Relapsers & & \\
\hline & $(\mathrm{N})$ & $(\mathrm{N})$ & $X^{2}$ & $p$ \\
\hline \multicolumn{5}{|l|}{ Gender } \\
\hline Male & 22 & 22 & .58 & .474 \\
\hline Female & 11 & 16 & & \\
\hline \multicolumn{5}{|l|}{ Ethnicity } \\
\hline White & 26 & 34 & 1.54 & .325 \\
\hline Minority & 7 & 4 & & \\
\hline \multicolumn{5}{|l|}{ Marital Status } \\
\hline Currently Married & 11 & 19 & .41 & .635 \\
\hline Currently Single & 22 & 19 & & \\
\hline \multicolumn{5}{|l|}{ Employment } \\
\hline Currently Employed & 12 & 12 & .01 & 1.00 \\
\hline Currently Unemployed & 18 & 19 & & \\
\hline
\end{tabular}


Table 7

Differences between Relapsers and Abstainers

\begin{tabular}{|c|c|c|c|c|c|c|c|c|}
\hline \multirow[b]{2}{*}{ Variables } & \multicolumn{3}{|c|}{ Relapsers } & \multicolumn{3}{|c|}{ Abstainers } & \multirow[b]{2}{*}{$\underline{t}$} & \multirow[b]{2}{*}{$p$} \\
\hline & $\underline{\mathrm{M}}$ & $\underline{\mathrm{SD}}$ & $\underline{\mathrm{n}}$ & $\underline{\mathrm{M}}$ & $\underline{\mathrm{SD}}$ & $\underline{\mathrm{n}}$ & & \\
\hline Age & 36.1 & $(11.9)$ & 33 & 42.9 & $(12.6)$ & 38 & 2.14 & $.036^{*}$ \\
\hline Education & 11.9 & $(1.5)$ & 33 & 12.4 & $(2.1)$ & 38 & .92 & .363 \\
\hline Previous Treatments & 3.2 & $(6.5)$ & 33 & 1.0 & $(1.2)$ & 38 & -1.99 & .052 \\
\hline SAAST Total & 23.0 & $(5.7)$ & 33 & 21.1 & $(6.2)$ & 38 & -1.29 & .201 \\
\hline AAQ Total & 77.8 & $(12.1)$ & 33 & 72.8 & $(13.9)$ & 38 & -1.61 & .112 \\
\hline BAI Total & 28.4 & $(16.2)$ & 33 & 18.5 & $(10.5)$ & 38 & -3.08 & $.003^{*}$ \\
\hline BDI Total & 20.6 & $(11.9)$ & 33 & 16.0 & ( 9.0$)$ & 38 & -1.85 & .069 \\
\hline CSI-problem solving & 24.2 & $(5.3)$ & 33 & 25.4 & $(6.3)$ & 38 & .87 & .386 \\
\hline CSI-social support & 22.1 & $(6.1)$ & 33 & 23.4 & $(5.2)$ & 38 & 1.37 & .176 \\
\hline CSI-avoidance & 23.2 & $(4.6)$ & 33 & 21.3 & $(4.2)$ & 38 & -1.82 & .073 \\
\hline LES-negative & 10.0 & ( 9.7) & 26 & 4.4 & $(5.0)$ & 36 & -2.72 & $.010^{*}$ \\
\hline LES-positive & 10.9 & $(7.8)$ & 26 & 14.6 & $(6.9)$ & 36 & $1 / 97$ & .054 \\
\hline
\end{tabular}


Table 8

Intercorrelations Among Predictor Variables and Relapse Criterion Variable
1.
2. 3.
4. 5 .
6. 7.
8.
9.
10.
11. 12 .

1. Age

2. Education $\quad .063$

3. Previous Treatments

$$
-.004-.154
$$

4. SAAST

$.121 \quad .010 \quad .423^{* *}$

5. AAQ

$\begin{array}{llll}-.196 & -.013 & .081 & .149\end{array}$

6. BAI

$\begin{array}{lllll}-.102 & -.158 & .201 & .319^{* *} & .363^{* *}\end{array}$

7. BDI

$\begin{array}{llllll}-.027 \quad .100 \quad .171 \quad .156 \quad .505^{* *} & .612^{* * *}\end{array}$

8. CSI Problem Solving

$\begin{array}{lllllll}-.059 & .093 & .068 & .002 & -.326 * * & -.145 & -.163\end{array}$

9. CSI Social Support

$\begin{array}{llllllll}-.179 & .242 * & -.136 & .056 & -.196 & .089 & -.039 & .552 * *\end{array}$

10. CSI Avoidance

$\begin{array}{lllllllll}-.086 & -.047 & .029 & .058 & .439 * * & .323 * * & .371 * * & -.232 & -.234 *\end{array}$

11. LES Negative Events $\begin{array}{llllllllll}.028 & -.048 & .028 & .322 * & .125 & .371 * * & .252 * & .012 & .168 & .112\end{array}$

12. LES Positive Events $\begin{array}{llllllllllll}-.326 * * & -.077 & -.174 & -.160 & -.031 & -.064 & -.137 & .172 & .275^{*} & -.048 & -.172\end{array}$

13. Relapse. $-.249 *-.110$ $.232 \quad .154 \quad .190$ $.348^{* *} .21$ $-.105$ $\begin{array}{lll}-.162 & .214 \quad .360 * *-.246\end{array}$

$* p<.05 . * * p<.01$. 
associated with other predictor variables, significantly correlating with the SAAST $(r=.32, p=$ $.007)$, the AAQ $(r=.36, p=.002)$, the BDI $(r=.61, p=.000)$, CSI-avoidance $(r=.323, p=$ $.006)$, and LES-negative $(r=.37, p=.003)$. Along with correlating with the BAI, the BDI also significantly correlated with a number of predictor variables. There were significant positive correlations between the BDI and gender $(r=.29, p=.015)$, AAQ total $(r=.51, p=.000)$, CSIavoidance $(r=.37, p=.001)$, and LES-negative $(r=.25, p=.048)$.

Of special interest was the degree to which the AAQ correlated with the CSI.

Specifically, the AAQ was hypothesized to positively correlate with avoidant coping strategies as measured by the avoidance scale of the CSI (CSI-avoidance), and to negatively correlate with more active problem-solving coping strategies measured by the CSI-positive scale. As demonstrated in Table 8, these hypotheses were born out, with the AAQ showing a moderate (particularly given the sample size) positive correlation with CSI-avoidance $(r=.44, \mathrm{p}<.01)$, and a negative correlation $(r=-.33, p<.01)$ with CSI-problem-solving.

\section{Multivariate Analyses}

Four discriminant function analyses were conducted to better understand the dimensions upon which the two outcome groups differed. The first was a standard discriminant function analysis with all predictor variables entered simultaneously. This procedure reveals the linear combination of variables that maximally discriminates between relapsers and non-relapsers. The second hierarchical discriminant function analysis explored the particular contribution of experiential avoidance in differentiating between relapsers and non-relapsers. Based on this analysis, a third hierarchical discriminant function analysis was conducted to explore the effects of an interaction between experiential avoidance and negative life events. The fourth hierarchical discriminant function analysis served both exploratory and practical purposes. That is, those 
variables shown to be significant predictors of group differences (by both initial univariate analyses and their loadings on the omnibus discriminant function analysis) were more fully examined. For practical purposes, predictor variables were separated in the analysis such that those present at the time of intake were assessed apart from unfixed or alterable factors that occurred after discharge.

In order to understand the overall and relative predictive power of the variables examined in the present project, a standard full model discriminant function analysis was conducted. When all variables were simultaneously entered in the discriminant analysis, the resulting discriminant function $\left(\mathrm{X}^{2}(17)=33.23, \mathrm{p}=.011\right)$ accounted for $48 \%$ of the between-group variability and accurately classified $84 \%$ of the cases. That is, 19 of the 26 subjects who relapsed were identified, and 33 of the 36 subjects who abstained were classified correctly.

Table 9 presents the loading matrix of correlations between predictors and the omnibus discriminant function. The matrix suggests that LES-negative $(r=-.41)$, total score on the BAI $(r$ $=-.40)$ and subject age $(r=.39)$ are the most influential components in differentiating relapsers from non-relapsers. Relapsers appear to experience more negative life events than do nonrelapsers $($ mean $=10.01$ vs. 6.73$)$, are younger $($ mean $=33.85$ vs. 39.10 for non-relapsers), and endorsed greater anxiety symptoms at intake (mean $=27.77$ vs. 22.06$)$ than did non-relapsers. The next strongest loadings were for aftercare $(r=.27), A A Q$ total scores $(r=-.26)$, BDI total scores $(r=-.24)$ and number of previous treatments $(r=-.22)$. Based on these results, relapsers were less likely to receive treatment after discharge, reported greater degrees of emotional avoidance $($ mean $=79.35$ vs. 75.63 for non-relapsers), were more depressed $($ mean $=20.52$ vs. 17.81), and had experienced more addiction-related treatment programs prior to this study than had non-relapsers (means $=2.73$ and 1.73 respectively). 
Table 9

$\underline{\text { Standard Discriminant Function Analysis of Relapsers and Non-Relapsers }}$

\begin{tabular}{|c|c|c|c|c|c|c|c|}
\hline Predictors & $\begin{array}{l}\text { Standardized } \\
\text { Discriminant } \\
\text { Function } \\
\text { Coeefficients }\end{array}$ & $\begin{array}{l}\text { Correlation } \\
\text { with } \\
\text { Discriminant } \\
\text { Function }\end{array}$ & $\begin{array}{l}\text { Wilks' } \\
\text { Lamda }\end{array}$ & $X^{2}$ & (df) & $p$ & $\begin{array}{l}\text { \% Correctly } \\
\text { Classified }\end{array}$ \\
\hline LES-negative & -.528 & -.407 & .525 & 33.23 & (17) & .011 & 83.9 \\
\hline BAI & -.187 & -.405 & & & & & \\
\hline Age & .801 & .390 & & & & & \\
\hline Aftercare & .402 & .272 & & & & & \\
\hline LES-positive & .598 & .268 & & & & & \\
\hline AAQ & -.198 & -.258 & & & & & \\
\hline BDI & .101 & -.240 & & & & & \\
\hline Previous Treatment & -.192 & -.214 & & & & & \\
\hline CSI-avoidance & -.014 & -.195 & & & & & \\
\hline Race & -.270 & -.172 & & & & & \\
\hline SAAST & -.004 & -.165 & & & & & \\
\hline Education & .104 & .134 & & & & & \\
\hline Marital Status & -.034 & .134 & & & & & \\
\hline CSI-problem-solving & .038 & .085 & & & & & \\
\hline CSI-social support & .015 & .082 & & & & & \\
\hline Gender & .259 & -.007 & & & & & \\
\hline
\end{tabular}

Note. Variables ordered by strength of loading on discriminant function correlation matrix 
The central hypothesis of the present project was that experiential avoidance would differentiate subjects who relapsed from those who did not. Sequential discriminant function analyses were used to examine whether experiential avoidance contributed to the differentiation between outcome groups. Because the variables thought to represent experiential avoidance (i.e., AAQ, avoidant coping, and negative life events) did not load as strongly as several other variables on the omnibus discriminant function, they were entered first in order to capitalize on potential shared variance with more strongly loading variables. As can be seen in Table 10, the experiential avoidance variables were also entered sequentially in order to discern the particular effects of each. Not surprisingly, given the results of the univariate tests and omnibus discriminant function, entry of subjects' AAQ scores did not result in a significant discriminant function $\left(\mathrm{X}^{2}(1)=2.52, p=.112\right)$. The AAQ accounted for $4 \%$ of the variance between relapsers and non-relapsers, and correctly classified $55 \%$ of the cases. The discriminant function generated with additional entry of the avoidant coping measure (CSI-avoidance) was also non-significant $\left(\mathrm{X}^{2}(2)=4.02, p=.134\right)$, and the combined variables accounted for only $6 \%$ of the variance between outcome groups. When the measure of negative life events (LES-negative) was entered, the resulting discriminant function was significant $\left(\mathrm{X}^{2}(3)=10.99, p=.012\right)$. This variable accounted for an additional $11 \%$ of the variance between groups. All told, the variables thought to represent experiential avoidance accounted for $17 \%$ of the variance between relapsers and nonrelapsers, and the resulting discriminant function correctly classified $66 \%$ of the cases. The correctly classified cases consisted primarily of individuals who did not relapse, with 31 of 36 non-relapsers correctly classified compared with only ten of 16 relapsers.

Because the occurrence of negative life events appeared to discriminate relapsers from non-relapsers, the occurrence of positive life events (measured by LES-positive) were also 
Table 10

Hierarchical Discriminant Function Examining Experiential Avoidance

\begin{tabular}{|c|c|c|c|c|c|c|}
\hline Predictors & Eigenvalue & $\begin{array}{l}\text { Wilkes' } \\
\text { Lamda }\end{array}$ & $X^{2}$ & (df) & $p$ & $\begin{array}{c}\% \text { Correctly } \\
\text { Classified }\end{array}$ \\
\hline
\end{tabular}

Step 1
AAQ
$.037 \quad .964$
$2.52 \quad(1)$
.112
54.9

Step 2

AAQ

.061

.943

4.02

(2)

.134

63.4

CSI-avoidance

Step 3

AAQ

.207

.829

10.99 (3)

.012

66.1

CSI-avoidance

LES-negative

Step 4
AAQ
.257
CSI-avoidance
.795
$13.29(94)$
.010
74.2
LES-negative
LES-positive

Step 5
AAQ
.262
.793
13.24 (6)
.039
74.2
CSI-avoidance
LES-negative
LES-positive
CSI-problem solving
CSI-social support 
examined. This variable accounted for an additional $4 \%$ of the variance between groups (for a total of $21 \%)$, and the resulting equation $\left(\mathrm{X}^{2}(4)=13.288, p=.010\right)$ correctly classified $74 \%$ of cases as relapsers or non-relapsers (12 of 26 relapsers and 34 of 36 non-relapsers). Similarly, to contrast the influence of other coping strategies with avoidant coping, the CSI-problem solving and CSI-social support variables were entered into the analysis. These variables did not significantly add to the discriminant equation $\left(\mathrm{X}^{2}(5)=13.24, p=.039\right)$. Table 11 presents the correlation matrix between these variables and resulting discriminant function.

One question that arose from the above analysis (and from the central hypothesis of this study) was whether the impact of negative life events on later relapse was due to subjects' emotional avoidance. That is, whether negative life events had greater negative impact (as represented by subsequent relapse) in emotionally avoidant individuals compared with less avoidant individuals. To examine this question a sequential discriminant function analysis was conducted in order to compare the predictive power of negative life events with the interaction of negative life events and emotional avoidance. To this end, LES-negative was entered on step 1 of the analysis, and as seen in Table 12 , resulted in a significant discriminant function $\left(\mathrm{X}^{2}(1)=8.25\right.$, $p=.004)$. This equation explained $21 \%$ of the variance between groups and correctly classified $68 \%$ cases (12 of 26 relapsers and 34 of 36 non-relapsers). In step 2 the interaction between the AAQ and LES-negative was entered, also resulting in a significant equation $\left(\mathrm{X}^{2}(2)=14.23, p=\right.$ $.001)$. This interaction explained an additional $8 \%$ of the variance between groups, and correctly classified 12 of 26 relapsers and 33 of 36 non-relapsers (for a total of 73\%). As shown in Table 13, the correlation matrix of this equation demonstrated that subjects who endorsed greater emotional avoidance and more negative life events were more likely to relapse than those who did 
Table 11

Discriminant Function Coefficients and Correlations for Predictors Entered in Hierarchical

Analysis \#1

\begin{tabular}{lc}
\hline & $\begin{array}{c}\text { Standardized Discriminant } \\
\text { Function Coefficients }\end{array}$ \\
Predictors* & $\begin{array}{c}\text { Correlation with } \\
\text { Discriminant Function }\end{array}$ \\
\hline
\end{tabular}

Step 2

CSI-avoidance

AAQ

Step 3

LES-negative

AAQ

CSI-avoidance

Step 4

LES-negative

LES-positive

AAQ

CSI-avoidance
.681

.502

, 820

.423

.188

.694

$-.446$

.396

Step 5

LES-negative

LES-positive

AAQ

CSI-avoidance

CSI-problem solving

CSI-social support
.398

.151

.719

$-.416$

.108

$-.156$
.760

$-.449$

.482

.890

.785

.849

.538

.407

.754

$-.496$

.478

.361

$-.158$

$-.153$

$\underline{\text { Note. }}$ Variables ordered according to strength of loading on discriminant function correlation matrix 
Table 12

Hierarchical Discriminant Function Examining Interaction between Experiential Avoidance and Negative Life Events

\begin{tabular}{|c|c|c|c|c|c|c|}
\hline Predictors & Eigenvalue & $\begin{array}{l}\text { Wilkes' } \\
\text { Lamda }\end{array}$ & $X^{2}$ & (df) & $p$ & $\begin{array}{c}\% \text { Correctly } \\
\text { Classified }\end{array}$ \\
\hline \multicolumn{7}{|l|}{ Step 1} \\
\hline LES-negative & .149 & .870 & 8.25 & (1) & .004 & 67.7 \\
\hline \multicolumn{7}{|l|}{ Step 2} \\
\hline $\begin{array}{l}\text { LES-negative } \\
\text { AAQ x LES-negative }\end{array}$ & .273 & .786 & 14.23 & (2) & .001 & 72.6 \\
\hline
\end{tabular}

Table 13

Discriminant Function Coefficients and Correlations for Predictors Entered in Hierarchical

Analysis \#2

\begin{tabular}{lcc}
\hline & $\begin{array}{c}\text { Standardized Dicriminant } \\
\text { Function Coefficients }\end{array}$ & $\begin{array}{c}\text { Correlation with } \\
\text { Discriminant Function }\end{array}$ \\
\hline
\end{tabular}

Step 2

AAQ x LES-negative

2.095

.916

LES-negative

$-1.245$

.739 
not. Importantly, the AAQ and LES-negative interaction loaded more strongly in the equation than did LES-negative alone.

The sequential discriminant analyses described above examined the specific hypothesis of this project. However, this research effort was fundamentally driven by an awareness of the significant relapse problem and the lack of data regarding the causes of this behavior. Hence, any factors associated with relapse were considered important and deserving of further attention. Because the omnibus analysis revealed the BAI to be a strong contributor to differentiating outcome groups, a second sequential discriminant function analysis, presented in Table 14, was conducted to further examine the effects of this variable. In addition, this analysis attempted to usefully illuminate factors that can be manipulated to reduce relapse rates. That is, along with exploring the effects of the BAI, the following analysis separates variables that were present at time of intake, when subjects were just beginning an inpatient addiction treatment program, from those that occurred after discharge. To control for the effects of age, this intrinsic variable was entered before the BAI, and resulted in a significant discriminant function $\left(\mathrm{X}^{2}(1)=4.40, p=\right.$ .036) that explained $6 \%$ of the variance between groups and correctly classified $66 \%$ of the cases. The BAI (administered during the initial assessment) was entered next $\left(\mathrm{X}^{2}(2)=12.43, p=.002\right)$, and accounted for an additional $11 \%$ of the variance between groups (classifying $69 \%$ of the cases correctly). That is, 15 of 26 relapsers were correctly identified, and 28 of 36 non-relapsers were correctly classified. Next the BDI (also administered at the outset of the study) was entered, but the inclusion of this variable did not add to the explained variance between outcome groups $\left(\mathrm{X}^{2}\right.$ $(2)=12.34, p=.006)$. The question of whether the negligible effects of the BDI were due to shared variance with the BAI is answered by Table 15. The presented loading matrix of 
Table 14

Hierarchical Discriminant Function Examining the BAI and Other Strong Predictors

\begin{tabular}{|c|c|c|c|c|c|c|}
\hline Predictors & Eigenvalue & $\begin{array}{l}\text { Wilkes' } \\
\text { Lamda }\end{array}$ & $X^{2}$ & (df) & $p$ & $\begin{array}{c}\% \text { Correctly } \\
\text { Classified }\end{array}$ \\
\hline
\end{tabular}

Step 1
Age
$.066 \quad .938$
$4.40 \quad(1)$
.036
66.2

Step 2

Age

.201

.833

12.43 (2)

.002

69.0

BAI

Step 3

$\begin{array}{llllll}\text { Age } & .201 & .833 & 12.36(3) & .006 & 67.6 \\ \text { BAI } & & & & & \\ \text { BDI } & & & & & \end{array}$

Step 4

Age

.333

.750

16.68 (4)

.002

74.2

BAI

BDI

Aftercare

Step 4

Age

.483

.674

$22.66(5)$

.000

74.2

BAI

BDI

Aftercare

LES-negative

Step 5

Age

$.729 \quad .578$

31.22 (6)

.000

80.6

BAI

BDI

Aftercare

LES-negative

LES-positive 


\section{Table 15}

Discriminant Function Coefficients and Correlations for Predictors Entered in Hierarchical Analysis \#3

\begin{tabular}{lcc}
\hline & $\begin{array}{c}\text { Standardized Discriminant } \\
\text { Function Coefficients }\end{array}$ & $\begin{array}{c}\text { Correlation with } \\
\text { Piscriminant Function }\end{array}$ \\
\hline
\end{tabular}

Step 2

BAI

Age

Step 3

BAI

Age

BDI
818

$-.561$

.789

$-.562$

.049
.828

$-.575$

.827

$-.575$

.496

Step 4

BAI

Age

$-.606$

$-.665$

.604

.423

$-.056$

BDI

Step 5

LES-negative

$-.594$

$-.351$

.610

.400

$-.012$
$-.555$

$-.552$

.531

.371

.327

Note. Variables ordered according to strength of loading on discriminant function correlation matrix 
correlations between these three predictors and the discriminant function demonstrates that the BAI $(r=.83)$ loaded much more strongly than did the BDI $(r=.49)$.

The three variables entered at this point in the analysis (i.e., age, BAI, BDI) represent factors that were present at the outset of treatment, whereas the final three steps involved factors that occurred after discharge. Aftercare (indicating whether or not subjects received additional addiction-related treatment after discharge) was entered on the next step of the analysis and accounted for an additional $8 \%$ of the variance between relapsers and non-relapsers. This discriminant function was significant $\left(\mathrm{X}^{2}(4)=16.68, p=.002\right)$ and correctly classified $74 \%$ of the cases (16 of 26 relapsers and 30 of 36 non-relapsers). LES-negative was entered on the next step, adding an additional $8 \%$ of explained variance, so that the generated discriminant function $\left(\mathrm{X}^{2}(5)\right.$ $=22.66, p=.000$ ) accounted for $33 \%$ of the variance between outcome groups and classified $74 \%$ of the cases correctly (14 of 26 relapsers and 32 of 36 non-relapsers). LES-positive was entered on the final step, accounting for an additional $9 \%$ of the variance between groups $\left(\mathrm{X}^{2}(6)\right.$ $=31.22, p=.000)$. In total, the discriminant function resulting from the second sequential discriminant analysis accounted for $42 \%$ of the variance between relapsers and non-relapsers $\left(\mathrm{X}^{2}\right.$ $(5)=31.22, p=.000$ ), and classified $81 \%$ of the cases correctly. In other words, this discriminant function correctly identified 18 of the 26 subjects who relapsed and 32 of the 36 individuals who did not.

\section{$\underline{\text { Discussion }}$}

\section{$\underline{\text { Conclusions }}$}

The main focus of this project was to explore experiential avoidance as a potential factor in relapse to alcohol dependence. The central hypothesis, that experiential avoidance would differentiate relapsers from non-relapsers three months following inpatient addiction treatment, 
was not supported by the data. Of the three variables thought to represent emotional avoidance, only negative life events significantly differentiated relapsers from non-relapsers. The measure specifically assessing experiential avoidance, the AAQ, did not significantly discriminate relapsers from non-relapsers, nor did the avoidant coping scale of the CSI.

It is possible the AAQ was not a significant predictor because experiential avoidance is not actually related to alcohol dependence relapse. Although this contradicts the reports of many relapsers who identified negative mood states as the main reason for resuming their alcohol use (Annis \& Davis, 1988; Cunningham et al., 1995; Marlatt \& Gordon, 1985), it is possible that these reports reflect a commonly held belief rather than actual fact. That is, given the widely accepted theory that many individuals drink to self-medicate, individuals who relapse may automatically attribute their relapse to a negative mood state when asked to provide reasons for their return to drinking. This tendency may be particularly likely when reasons for relapsing are assessed retrospectively (Matt, Vazques, \& Campbell, 1992). As discussed in the literature review however, prospective studies have also supported the association between negative mood states and relapse to alcohol dependence (Hodgins et al., 1985; Vuchinich \& Tucker, 1996).

A second reason subjects' scores on the AAQ did not differentiate relapsers from nonrelapsers may be due to the measure itself. The AAQ is still under development, and its psychometrics are relatively unproven. For example, the measure's reliability has not been established beyond a cross-validation effort by its developers (this confirmed a single factor solution, with avoidance items loading positively at one end, and acceptance items loading negatively at the other, Hayes et al., in press). It is also challenging to achieve content validity with an assessment of a new or untested area, especially for a complex construct. The authors report the AAQ has concurrent validity, as demonstrated by its ability to predict whether patients 
would score above or below clinical cutoffs for the BAI and BDI (Hayes, Strosahl, \& Wilson, in press). However, this is more a demonstration of the measure's ability to correlate with psychopathology than experiential avoidance per sé. Convergent validity of the AAQ is suggested by a recent, as yet unpublished, study that assessed the relation between interoceptive sensitivity and emotional avoidance strategies. This study demonstrated that subjects who reported more distress due to bodily sensations (measured by the Anxiety Sensitivity Index and the Body Sensations Questionnaire) scored more highly on the AAQ (John Forsyth, personal communication, May 7, 1998). The results of the present study also moderately supported the measure's convergent validity, as subjects' AAQ scores positively correlated with the CSI avoidant coping scale, and negatively correlated with the CSI problem solving coping scale. In short, although there have been some supportive data regarding the ability of the AAQ to measure experiential avoidance, further validation efforts are needed before the AAQ can be declared psychometrically sound. Finally, it was observed during administration of the AAQ that subjects had difficulty completing it relative to other measures. Subjects' behavior while responding to AAQ items (e.g., slow rate of response, tentativeness, questions asked, etc.) suggest the readability and comprehension of this measure was less than optimal for the population studied.

A final explanation for the inability of the AAQ to significantly differentiate relapsers from non-relapsers is the possibility that the population studied does not lend itself to differentiation along an experiential avoidance dimension. The very fact that subjects were drawn from inpatient addiction treatment is evidence that these individuals were significantly alcohol-dependent. In addition, more than half of the subjects had received prior treatment for alcohol dependence. If experiential avoidance is indeed a factor in the maintenance of problematic drinking, it would be generally present in this population, and attempts to differentiate individuals along this dimension 
could prove difficult. Although norms for the AAQ are not available at this time, non-published AAQ scores from non-substance abusing populations strongly suggest that the average AAQ scores obtained in the current effort (mean $=79.3$ for relapsers and 73.0 for non-relapsers) were far higher than in non-substance-abusing populations. The mean AAQ score for females at a large HMO $(n=237)$ was 67.9 , and 65.5 for male clients $(n=105)$. And although the following figures cannot be generalized to the present population, it is also interesting that the mean AAQ scores obtained from large samples of college undergraduates were also well below the mean scores obtained in this study. The mean AAQ score in a large $(n=304)$ non-clinical sample of college undergraduates was 55.7, and female students at a university counseling center $(n=277)$ had an average AAQ score of 64.2. Male students $(n=162)$ at the same counseling center had an average score of 61.9 (personal communication, Richard Bisset, April 25, 1999).

In sum, the lack of predictive power of the AAQ in this study may be due to a ceiling effect present in the sample. The measure may better discriminate problematic drinkers from nondrinkers, or non-problematic drinkers. In addition, experiential avoidance may be usefully viewed as a maintaining factor in alcohol dependence versus a predictor of relapse in dependent individuals.

If the inpatient addiction treatment sample used in this study was experientially avoidant as a whole, it would follow that these individuals would be particularly vulnerable to the impact of negative life events, and would have more difficulty abstaining than those who experienced fewer negative events. This hypothesis was supported by the results of the present study. An association between negative life events and relapse was clear, with the LES-negative consistently differentiating among relapsers and non-relapsers. In addition, the interaction between negative life events and experiential avoidance further differentiated outcome groups. That is, avoidant 
individuals who experienced negative life events were more likely to relapse than less avoidant individuals who also experienced negative life events. Unfortunately, this finding was undermined by a lack of temporal information regarding the occurrence of these events. That is, no attempt was made to determine to what extent negative events preceded relapses, only whether such events had occurred in the three months prior to follow-up. It is possible that the obtained results reflect the bi-directional nature of relapse and stressful events, and that a relapse (a) began or influenced a chain of negative events, and/or b) contributed to the perception of events as being negative experiences.

If in fact negative events do precipitate relapse, the question remains as to why. Perhaps, as suggested by Vuchinich and Tucker (1996), such events and their sequelae result in less access to reinforcers supportive of abstinence, such as aftercare, positive social support networks, and/or opportunities to engage in more adaptive activities. Yet again, as posited in the present hypothesis, the internal phenomena experienced in response to negative life events may lead to relapse if the individual in question is intolerant of such unpleasant internal experiences.

If the effects of negative life events are due to the unpleasant subjective states that result, then positive events might be seen as moderating relapse. Because the cognitive, affective, and physiological states experienced in the aftermath of positive events are pleasant, they would not require fixing with a mood-altering drug. The more positive events an individual experiences, the less need to alter their subjective experience. The results of this study supported previous work (Rosenberg, 1983; Vuchinich and Tucker, 1996) that found the occurrence of positive events was associated with remaining abstinent. The possibility remains however, that the occurrence and perceived benefits from positive events is at least partially an artifact of being alcohol-free. Clearly, further research is needed to shed light on these issues. 
Contrary to previous research suggesting that an individual's coping style is a factor in relapse, coping style was not shown to significantly differentiate relapsers from non-relapsers in this study. However, trends were in the expected direction, with relapsers being more likely to engage in avoidant coping, and less likely to actively cope by problem solving than were nonrelapsers. As previously discussed, measuring this construct has been historically problematic and the results of the present study may attest to this ongoing difficulty. It is also possible that the 3month period between the initial assessment and the follow-up was not long enough to reveal the importance of different coping strategies. It should be noted that Brown et al. (1994) found coping (as one facet of a "psychological vulnerability" dimension) did not differentiate relapsers from non-relapsers at three months after an initial assessment, but did significantly differentiate relapsers from non-relapsers one year after treatment. In order to fully examine the effects of coping style on relapse, a more longitudinal design may therefore be called for.

A consistent finding was that subject's anxiety level at time of intake, as measured by the BAI, significantly differentiated between those who had relapsed three months later and those who had not. The presence of anxiety in this population was not surprising, as the comorbidity of anxiety disorders and alcohol dependence has been well-documented (Brady \& Lydiard, 1993; Clark \& Sayette, 1993; Himle \& Hill, 1991, Wesner, 1990). However, the majority of the literature regarding the co-occurrence of anxiety and alcohol problems has arisen from studies focused on anxiety-disordered populations (Wesner, 1990), and anxiety as a predictor of alcohol dependence relapse has not been closely examined. In addition, the nature of the relation between anxiety and alcohol dependence is unclear at this point. For example, there is some evidence that anxiety is a consequence of alcohol dependence, as opposed to being a precipitant (Allan, 1995; Schuckit \& Hesselbrock, 1994). 
For the purposes of this study, it is interesting to consider a 1992 study conducted by LaBounty, Hatsukami, Morgan, \& Nelson. Alcoholics diagnosed with phobia and panic symptoms were found to have relapse rates similar to matched controls. However, the anxious subjects reported that they resumed drinking in order to cope with negative internal states. Brown, Irwin, \& Schuckit (1991) found that although relapsers and non-relapsers did not differ in levels of anxiety observed during treatment, relapsers reported significantly higher anxiety scores (on both state and trait measures) at a 3-month follow-up assessment. It should also be noted that much of the current interest in experiential avoidance was led by developments in the treatment of anxiety. For example, it has been shown that the avoidance of the unpleasant emotional, cognitive, and physiological effects of panic disorder serves to maintain and actually increase panic symptoms (Barlow, 1988). The recognized importance of the "fear of fear" in anxiety disorders has led to treatment protocols geared towards increasing one's exposure to, and tolerance of, unpleasant internal experiences (Barlow, D. H., \& Craske, 1994). It is possible the association between anxiety and substance abuse, and anxiety and relapse, is that experiential avoidance is a common denominator.

The finding that BAI scores are associated with later relapse offers an immediate and easily attained means of identifying individuals at risk. The association between anxiety at intake and relapse also strongly suggests the need for treatment of anxiety to be included concomitantly with treatment of alcohol dependence. Relapse prevention programs would do well to address attitudes and responses to anxiety as well as to substance abuse.

An interesting finding was that subjects' age significantly differentiated between relapsers and non-relapsers, with younger subjects significantly more likely to relapse than their older counterparts. Surprisingly, the majority of studies cited in the previous literature review did not 
report whether or not age significantly differentiated relapsers from non-relapsers. In addition, those that did reported contradictory findings. For example, Brown et al. $(1990,1994)$ found no age difference between relapsers and non-relapsers, nor did Hodgins et al. (1995). Similar to the present study however, Cooper et al. (1988) reported that relapsers were significantly younger than non-relapsers (means of 35.1 and 40.7, respectively). The influence of age therefor appears to be less than clear cut. In a study of the specific effects of age and cohort on problem drinking, Levenson, Aldwin, and Spiro (1998) found that while increasing age was generally associated with decreased alcohol consumption, the effects of age depended upon which cohort or time period was assessed. Although thorough examination of this factor was beyond the scope of the current project, the fact that age strongly differentiated relapsers from non-relapsers certainly invites closer study.

Consistent with clinical lore, subjects who participated in some form of aftercare were more likely to be abstinent. However, interpretation of this finding was impeded by the fact that (a) most of the subjects (19 out of 26 relapsers and 33 out of 36 non-relapsers) participated in some form of aftercare, and (b) no effort was made to systematically assess the type of treatment or other important characteristics such as frequency and duration of the aftercare. However, research that examined the influence of aftercare on addiction relapse more closely does support this finding (Brown et al., 1994; Cronkite and Moos, 1980, Ellis \& McClure, 1992).

\section{Limitations of this Study}

It is important to identify weaknesses of the present project so that future endeavors might benefit. Limitations of the present project included the following:

1. The central hypothesis of the study hinged upon an unrefined measure. The AAQ was under development at the outset of the study and remains so at its conclusion. The true import of the 
research findings cannot be determined due to the unanswered questions that remain regarding the validity and reliability of this measure. A more prudent approach would have been to focus on refining the measurement of experiential avoidance, rather than on whether this construct differentiates relapsers from non-relapsers. The cart may have been put before the horse, so to speak.

2. A control group for comparison of AAQ data would also have been helpful as previously discussed. Although this was considered beyond the scope of this project, lack of normative data did inhibit interpretation of the findings.

3. Subjects' mood ratings were not assessed. The incorporation of prospective mood ratings would have significantly enhanced the present project, offering the opportunity to assess the relationship between negative affect, the AAQ, negative life events, coping, and relapse.

4. More assiduous attention to the occurrence of negative life events and relapse might have yielded important data. For example, asking subjects who relapsed how soon this occurred after a negative life event (or if they in fact they did relapse after the event) would have been useful.

5. Similarly, the loss of income data was potentially important and could possibly have been avoided by discussion this variable with subjects and reassuring them of the confidentiality of their information.

6. Although it served the purposes of the present study, utilizing a three-month time frame for assessing relapse does not adequately assess the complexities of the relapse process. That is, those unfamiliar with the field of addiction might understandably interpret the revealed relapse rates as failed treatment. In actuality, both empirical and applied work have demonstrated that recovery from addiction is a process. Accurate depiction of relapse and recovery requires more fine-grained assessment over a longer period of time than that employed in the present study. 
Important distinctions with real treatment implications (e.g., between relapses and slips, the effectiveness of various coping strategies) might thereby be revealed.

\section{$\underline{\text { Summary and Future Directions }}$}

The end result of the current project is that the role of experiential avoidance in alcohol dependence relapse remains in question. The lack of empirical support in this study must be weighed against the persistent and pervasive conviction (held by addicts, mental health professionals, and addiction experts) that relapse often occurs in response to negative emotions. The fact that intolerance to negative affect is a widely reported reason for relapse should not be forgotten, particularly in light of the high recidivism rate seen in this population. Continued effort, improved methods, and refined experiential avoidance measures are badly needed to further explore experiential avoidance in this context. The following are tenable suggestions for future study:

1. The measurement of experiential avoidance must be refined. Because experiential avoidance includes cognitive, behavioral, physiological, and affective domains, the presence of these domains in the context of addiction and relapse must be established, as well as their relation to one another. The recent effort by Cooney at al. (1997) was a step in this direction, as this laboratory study demonstrated in vivo that subjects' reactivity to negative mood resulted in increased desire to consume alcohol. Additional work of this nature would greatly enhance the validity of experiential avoidance as a factor in relapse.

2. Related to the above challenge, a reliable and valid experiential avoidance instrument is needed. For example, the criterion-related validity of the AAQ remains in question and needs to be determined with the use of normative data. Continued efforts to establish convergent validity with the AAQ and other indices of experiential avoidance are also in order, such as the recent 
work by Forsyth et al. (personal communication, May 7, 1998) that linked the AAQ to interoceptive sensitivity and fears of bodily sensations. Confirmatory factor analyses with a variety of populations are needed as well.

3. Clarifying the association between anxiety, emotional avoidance, and relapse is also needed. For example, it may be that anxious individuals' baseline level of sensitivity to unpleasant private experiences is greater than for non-anxious individuals. That is, anxious alcohol-dependent individuals may be more experientially avoidant, and therefore more susceptible to relapse, than non-anxious individuals with alcohol dependence.

If the culpability of experiential avoidance is eventually confirmed, it is vital that this information be disseminated so that treatment programs can address this aspect of substance dependence relapse. Although many programs incorporate treatment components that address negative affect to some degree, it is not current practice to make it a central focus. In addition, a subtle yet crucial distinction exits between affect "management" and emotional acceptance. For example, many programs include various affect management techniques (e.g., anger control, stress reduction) as part of relapse prevention efforts. While such techniques might seem helpful on the surface, they inadvertently reinforce the message that unpleasant emotions need to be managed, handled, or altered in some way. Treatment targeting increased tolerance of unpleasant internal experiences may better pave the way for abstinence. As noted by Hayes, Wilson, Gifford, Follette, and Strosahl (1996), it is interesting that a central component of 12-step programs (the widely used and endorsed self-help support network known as AA) is acceptance. 
Unfortunately, alcohol dependence is a ubiquitous and firmly entrenched disorder.

Opportunities to explore experiential avoidance and other potential dimensions of relapse will no doubt remain plentiful. It is hoped the present effort engenders interest and ideas that will help to vanquish this debilitating problem. 


\section{References}

Aldwin, C. M., \& Revenson, T. A. (1987). Does coping help? A reexamination of the relation between coping and mental health. Journal of Personality and Social Psychology, 53, 337348.

Allan, C. A. (1995). Alcohol problems and anxiety disorders-A critical review. Alcohol and Alcoholism, 30, 145-151.

Amirkhan, J. H. (1990). A factor analytically derived measure of coping: The Coping Strategy Indicator. Journal of Personality and Social Psychology, 59, 1066-1074.

Amirkhan, J. H. (1994). Criterion validity of a coping measure. Journal of Personality Assessment, 1994, 242-261.

Annis, H. M., \& Davis, C. S. (1988). Assessment of expectancies. In D. M. Donovan, \& G. A. Marlatt (Eds.). Assessment of Addictive Behaviors. (pp. 84-111). New York: The Guilford Press.

Annis, H. M., Sklar, S. M., \& Moser, A. E. (1998). Gender in relation to relapse crisis situations, coping, and outcome among treated alcoholics. Addictive Behavior, 23, 127-131.

Barlow, D. H. (1988). Anxiety and It's Disorder: The Nature and Treatment of Anxiety and Panic. New York: The_Guilford_Press.

Barlow, D. H., \& Craske, M. G. (Mastery of Your Anxiety and Panic. New York: Guilford Press.

Beck, C. J. (1989). In. S. Smith (Ed.) Everyday Zen. San Francisco: HarperSanFranciso.

Beck, A. T., \& Steer, R. A. (1993a). Beck Depression Inventory Manual. New York: The Psychological Corporation, Harcourt Brace \& Company. 
Beck, A. T., \& Steer, R. A. (1993b). Beck Depression Inventory Manual. New York: The Psychological Corporation, Harcourt Brace \& Company.

- $\quad$ Billings, A. C., \& Moos, R. H. (1982). Stressful life events and symptoms: A longitudinal model. Health Psychology, 2, 99-117.

Billings, A. C., \& Moos, R. H. (1983). Psychosocial processes of recovery among alcoholics and their families: Implications for clinicians and program evaluators. Addictive Behaviors, 8, 205-218.

Booth, B. M., Blow, F. C., Cook, C. A., Bunn, J. Y., \& Forney, J. C. (1992). Age and ethnicity among hospitalized alcoholics: a nationwide study. Alcohol Clinical and Experimental Research, 16, 1029-1034.

Brady, K. T., \& Lydiard, R. B. (1993). The association of alcoholism and anxiety. Psychiatric Quarterly, 64, 135-149.

Breslin, F. C., O’Keefe, M. K., Burrel, L., Ratliff-Crain, J., \& Baum, A. (1995). Effects of stress and coping on daily alcohol use in women. Addictive Behaviors, 20, 141-147.

Brown, S. A., Vik, P. W., McQuaid, F. R., Patterson, T. L., \& Grant, I. (1990). Severity of psychosocial stress and outcome of alcohol treatment. Journal of Abnormal Psychology, 99 , $322-348$.

Brown, S. A., Irwin, M., Schuckit, M. A. (1991). Changes in anxiety among abstinent male alcoholics. Journal of Studies on Alcohol, 52, 55-61.

Brown, S. A., Vik, P. W., Patterson, T. L., Grant, I., \& Schuckit, M. A. (1994). Stress, vulnerability and adult alcohol relapse. Journal of Studies on Alcohol, 56, 538-545. 
Caetano, R., \& Schafer, J. (1996). DSM-IV alcohol dependence and drug abuse/dependence in a treatment sample of whites, blacks and Mexican Americans. Drug and Alcohol Dependence, 43, 93-101.

Childress, A. R., McLellan, A. T., Natalie, M., \& O’Brien, C. P. (1987). Mood states can elicit conditioned withdrawal and craving in opiate abuse patients. In L. S. Harris (Ed.), Problems of Drug Dependence 1986 (NIDA) Monograph Series No. 76 (pp. 137-144). Washington DC: US Government Printing Office.

Clark, D. B., \& Sayette, M. A. (1993). Anxiety and the development of alcoholism: Clinical and scientific issues. American Journal on Addiction, 2, 59-76.

Clark, K. K., Bormann, C. A., Cropanzano, R. S. \& James, K. (1995). Validation evidence for three coping measures. Journal of Personality Assessment, 65, 434-455.

Cooney, N. L., Litt, M. D., Morese, P. A., Bauer, L. O., Gaupp, L. (1997). “Alcohol cue reactivity, negative-mood reactivity, and relapse in treated alcoholic men. Journal of Abnormal Psychology, 106, 243-250.

. Cooper, M. L., Russell, M., George, W. H. (1988). Coping, expectancies, and alcohol abuse: A test of social learning formulations. Journal of Abnormal Psychology, 97, 218-230.

. $\quad$ Cooper, M. L., Russell, M., Skinner, J. B., Frone, M. R., \& Mudar, P. (1992). Stress and alcohol use: Moderating effects of gender, coping, and alcohol expectancies. Journal of Abnormal Psychology, 101, 139-152.

. Cronkite, R. C., \& Moos, R. H. (1980). Determinants of the posttreatment functioning of alcoholic patients: A conceptual framework. Journal of Counseling and Clinical Psychology, 48, 305-316. 
- Cunningham, J. A., Sobell, M. A., Sobell, L. C., Gavin, D. R., Annis, H. M. (1995).

Heavy drinking and negative affective situations in a general population and a treatment sample: Alternative explanations.

Davis, L. J., Hurt, R. D., Morse, R. M., \& O’Brien, P. C. (1987). Discriminant analysis of the self-administered alcoholism screening test. Alcoholism: Clinical and Experimental Research, $11,269-273$.

Davis, L. J., \& Morse, R. M. (1987). Patient-spouse agreement on the drinking behaviors of alcoholics. Mayo Clinical Proceedings, 62, 689-694.

Dohrenwend, B. S., Dohrenwend, B. P., Dodson, M., \& Shrout, P. E. (1984). Symptoms, hassles, social supports, and life events: Problems of confounded measures. Journal of Abnormal Psychology, 93. 222-230.

Donovan, D. M., \& Marlatt, G. A. (Eds.). (1988). Assessment of Addictive Behaviors. New York: The Guilford Press.

Ellis, D., \& McClure, J. (1992). In-patient treatment of alcohol problems-predicting and preventing relapse. Alcohol, 27, 449-456.

Farber, Khavari, \& Dougles (1980). A factor analytic study of reasons for drinking: Empirical validation of positive and negative reinforcement dimensions. Journal of Consulting and Clinical Psychology, 48, 780-781.

Folkman, S. \& Lazarus, R. S. (1980). An analysis of coping in a middle-aged community sample. Journal of Health and Social Behavior, 21, 219-239.

Hall, S. M., Havassy, B. E., \& Wasserman, D. A. (1990). Commitment to abstinence and acute stress in relapse to alcohol, opiates, and nicotine. Journal of Counseling and Clinical Psychology, 58, 175-181. 
Hayes, S. C., \& Melancon, S. M. (1989). Comprehensive distancing, paradox, and the treatment of emotional avoidance. In M. Ascher (Ed.) Paradoxical procedures in psychotherapy (pp. 184-218). New York: Guilford.

Hayes, S. C., \& Wilson, K. G., (1993). Some applied implications of a contemporary behavior-analytic account of verbal events. The Behavior Analyst, 16, 283-301.

Hayes, S. C., \& Wilson, K. G., (1994). Acceptance and commitment therapy: Altering the verbal support for experiential avoidance. The Behavior Analyst, 17, 289-303.

Hayes, S. C., Strosahl, K., \& Wilson, K. G. (in press). Acceptance and Commitment Therapy: Understanding and Treating Human Suffering. New York: Guilford Press.

Hayes, S. C., Wilson, K. G., Gifford, E. V., Follette, V. M. \& Strosahl, K. (1996). Experiential avoidance and behavioral disorders: A functional dimensional approach to diagnosis and treatment. Journal of Counseling and Clinical Psychology, 64, 1-48.

Himle, J. A., \& Hill. E. M. (1991). Alcohol abuse and the anxiety disorders: Evidence from the Epidemiologic Catchment Area Survey. Journal of Anxiety Disorders, 5, 237-245.

Hodgins, D. C., el-Guebaly, N., \& Armstrong, S. (1995). Prospective and retrospective reports of mood states before relapse to substance use. Journal of Counseling and Clinical Psychology, 63, 400-407.

Holahan, C. J., \& Moos, R. F. (1987). Personal and contextual determinants of coping strategies (1987). Journal of Personality and Social Psychology, 52, 946-955.

Horé, B. D. (1971). Life events and alcoholic relapse. British Journal of Addiction, 66, 83-88. Hurt, R. D., Morse, R. M., \& Swenson, W. M. (1980). Diagnosis of alcoholism with a self-administered alcoholism screening test. Mayo Clinical Proceedings, 55, 365-370. 
Jones-Webb, R. J., Hsiao, C. Y., \& Hannan, P. (1995). Relationships between socioeconomic status and drinking problems among black and white men. Alcohol Clinical Experimental Research, 19,623-7.

LaBounty, L. P., Hatsukami, D., Morgan, S. F., \& Nelson, L. (1992). Relapse among alcoholics with phobic and panic symptoms. Addictive Behavior, 17, 9-15.

Lazarus, R. S. (1990). Stress, coping, and illness. In H. S. Friedman (Ed.) Personality and Disease. New York: John Wiley \& Sons, Inc.

Levenson, M. R., Aldwin, C. M., Spiro, A. (1998). Cohort and period effects on alcohol consumption and problem drinking: Findings from the Normative Aging Study. Journal of Studies on Alcohol, 59, 712-722.

Linehan, M. M., (1993). Cognitive-behavioral treatment of borderline personality disorder. New York: The Guilford Press.

Litman, G. K., Eiser, J. R., Rawson, N. S., \& Oppenheim, A. N. (1979). Differences in relapse precipitants and coping behavior between alcohol relapsers and survivors. Behavior Research and Therapy, 17, 89-94.

Litman, G. K., Stapleton, J., Oppenheim, A. N., Peleg, M., \& Jackson, P. (1983). Situations related to alcoholism relapse. British Journal of Addiction, 78, 381-389.

Mackay, P. W., \& Marlatt, G. A., (1991). Maintaining sobriety: Stopping is starting. The International Journal of the Addictions, 25, 1257-1276.

Marlatt, G. A. (1994). Addiction, mindfulness, and acceptance. In S. C. Hayes, N. S. Jacobson, V. M. Follette, \& M. J. Dougher (Eds.). Acceptance and change: Content and contest in psychotherapy. Reno, NV: Context Press. 
Marlatt, G. A. (1996). Models of relapse and relapse prevention: A commentary. Experimental and Clinical Psychopharmacology, 4, 55-60.

Marlatt, G. A., \& Gordon, J. R. (1980). Determinants of relapse: Implications for the maintenance of behavior change. In P. O. Davidson \& S. M. Davidson (Eds.). Behavioral medicine: Changing health lifestyles (pp. 410-452). New York: Brunner/Mazel.

- Marlatt, G. A., \& Gordon, J. R. (Eds.). (1985). Relapse Prevention. New York: The Guilford Press.

Matt, G. E., Vazquez, C. \& Campbell, W. K. (1992). Mood congruent recall of affectivity toned stimuli: A meta-analytic review. Clinical Psychology Review, 12, 227-255.

McKirnan, D. J., Peterson, P. L. (1988). Stress, expectancies, and vulnerability to substance abuse: A test of a model among homosexual men. Journal of Abnormal Psychology, 97, 461-466.

Meyers, M. G., \& Brown, S. A. (1990a). Coping responses and relapse among adolescent substance abusers. Journal of Substance Abuse, 3, 177-189.

Meyers, M. G., \& Brown, S. A. (1990b). Coping and appraisal in potential relapse situations among adolescent substance abusers following treatment. Journal of Adolescent Chemical Dependency, 1, 95-115.

Moos, R. H., Fenn, C. B., Billings, A. G., \& Moos, B. S. (1989). Assessing life stressors and social resources: Applications to alcoholic patients. Journal of Substance Abuse, 1, 135-152.

Mulford, H. A. (1983). Stress, alcohol intake and problem drinking in Iowa. In L. A. Poherecky \& J. Brick (Eds.), Stress and alcohol use. Proceedings of the First International Symposium on Stress and Alcohol Use (pp. 321-332). New York: Elsevier. 
O’Doherty, F., \& Davies, J. B. (1987). Life events and addiction: A critical review. British Journal of Addiction, 82, 127-137.

- $\quad$ Rosenberg, H. (1983). Relapsed versus non-relapsed alcohol abusers: coping skills, life events, and social support. Addictive Behaviors, 8, 183-186.

Rubin, A., Stout, R. L., Longabaugh, R. (1996). Gender differences in relapse situations. Addiction, 91, 111-120.

Sarason, I. G., Johnson, J. H., Seigal, J. M. (1978). Assessing the impact of life changes: Development of the Life Experiences Survey. Journal of Consulting and Clinical Psychology, 46, 932-946.

Schuckit, M. A., \& Hesselbrock, V. (1994). Alcohol dependence and anxiety disorders: What is the relationship? American Journal of Psychiatry, 151, 1723-1734.

Schwarzer, R., \& Schwarzer, C. (1996). A critical survey of coping instruments. In M. Zeidner \& N. Endler (Eds.) Handbook of Coping: Theory, research, applications. (pp. 107-132). New York

Stasiewicz, P. R., \& Maisto, S. A. (1993). Two-factor avoidance theory: The role of negative affect in the maintenance of substance use and substance use disorder.

Swenson, W. M., \& Morse, P. M. (1975). The use of a self-administered alcoholism screening test (SAAST) in a Medical Center. Mayo Clinical Proceedings, 50, 204-208.

Tabachnick, B. G., \& Fidel, L. S. (1996). Using multivariate statistics (3 ${ }^{\text {rd }}$ ed.). New York: HarperCollins College Publishers.

- Tucker, J. A., Vuchinich, R. E. (1992). Substance abuse relapse: Theory and clinical application. In R. R. Watson (Ed.). Drug and Alcohol Abuse Reviews, Vol. 4: Drug Abuse Treatment (pp.71-98). Totowa, NJ: The Humana Press, Inc. 
Vitaliano, P. P., Russo, J., Carr, J. E., Maiuro, R. D., \& Becker, J. (1985). The Ways of Copings Checklist: Revision and psychometric properties. Multivariate Behavioral Research, 20, 3-26.

Vuchinich, R. E., \& Tucker, J. A. (1996). Alcoholic relapse, life events, and behavioral theories of choice: A prospective analysis. Experimental and Clinical Psychopharmacology, 4, 1928.

Wesner, R. B. (1990). Alcohol use and abuse secondary to anxiety. Psychiatric Clinics of North America, $\underline{13,699-713 .}$ 
Appendix A

Curriculum Vitae 


\section{Curriculum Vitae \\ Darrah Ann Westrup}

July, 1999

\section{Educational History}

1993 - present

May 1993

May 1985

Jan. - May 1984

\section{Clinical Experience}

Sept. '98 - Present
West Virginia University

Morgantown, WV

APA-approved Doctoral Program in Adult Clinical Psychology

Dissertation to be completed 5/99

San Jose State University

San Jose, CA

M.A.; Psychology

University of the Pacific

Stockton, CA

B.A.; English and French

Institute of European Studies

Paris, France

Course of study; French and English Literature
Psychology Intern - VA Palo Alto Health Care System, Palo Alto, CA Currently a multidisciplinary team member working with male combat veterans at the National Center for PTSD, Education and Clinical Laboratory Division. Clinical Responsibilities include co-leading war-zone focus groups and process groups, teaching affect management and communication skills groups, case management, assessment and report writing. Supervisor: Dorene Loew, Ph.D. A second rotation at the Family Therapy Center involves conducting couples and family therapy.

Responsibilities also include intake interviews, case conceptualization, and treatment coordination with outside agencies. Supervisors: Joan Ross, R.N., M.S., M.F.C.C; Douglas Rait, Ph.D., Mark Patterson, Ph.D.

Future rotations beginning March, '99: Addiction Treatment Services Responsibilities at this day treatment program will include group and individual therapy, psychoeducation, assessment, and interdisciplinary coordination and case management. Supervisor: Lou Moffet, Ph.D. Geriatric Evaluation and Management Unit. Responsibilities will include hospital-wide consultation and liaison, and individual and family therapy for older adults. Will also conduct evaluations and neuropsychological assessments. Supervisor: Jon Rose, Ph.D. 
May ‘97 - May ‘98

Aug. '96 - Aug. '97

May '95 - Aug. '96

Aug. '95 - Aug. '96
Graduate Psychologist - Hoier and Associates, Morgantown, WV Received practicum training (16 hrs. /wk.) at a busy private practice. Activities included individual, couple, family, and group therapy with adults and adolescents. Presenting problems included both Axis I and II disorders, including substance abuse (e.g., alcohol, cocaine, barbiturates, prescription drugs), depression, dissociative disorder, PTSD, borderline personality disorder and antisocial personality disorder. Many clients were victims of sexual and physical abuse and carried dual diagnoses. Regularly performed diagnostic interviewing, psychological testing and assessment, formulation of treatment plans, and written evaluations. Also assisted with billing procedures.

Supervisor: Tamara S. Hoier, Ph.D.

Graduate Practicum Student - Sharpe Psychiatric Hospital, Weston, WV This practicum placement (16 hrs. /wk. for one year) involved working closely with a neuropsychologist in an inpatient setting. Emphasis was on developing assessment skills, such as neuropsycholgical evaluations and diagnostic interviewing. Completed neuropsychological batteries tailored to the referral question. Also worked closely with a psychologist who as an interdisciplinary team member, designed and implemented behavioral treatment plans and a successful token economy system. Responsibilities included diagnostic interviewing, personality testing, cognitive intelligence testing, report writing and individual therapy.

Supervisors: Martin Boone, Ph.D.; Jim LePage, Ph.D.

Graduate Psychologist - Federal Corrections Institute, Morgantown, WV Completed a 15 -month (16 hrs. /wk.) practicum at this site. Conducted individual and group therapy with male inmates. Presenting problems were diverse, including personality and substance abuse disorders, as well as such difficulties as panic disorder, gender identity disorder, and parauresis. Facilitated three groups addressing substance abuse and issues related to impeding release. Regularly conducted intake interviews and screened applicants to a drug abuse program. Provided crisis intervention as needed.

Supervisors: Jeffrey Hammond, Ph.D., Director of Clinical Training; Dennis Becotte, Ph.D., Chief of Psychology.

Vertical Team Member - Post Traumatic Stress Disorder Team, Department of Psychology, West Virginia University, Morgantown, WV Member (one year) of a team targeting individuals with trauma-related symptoms. Responsibilities included team meetings and participation in case discussion and conceptualization. Served as co-therapist conducting exposure therapy with a client experiencing PTSD from a motor vehicle accident. Administered PTSD and other clinically related assessments, completed progress notes and treatment plans, and assisted with administrative procedures.

Supervisor: Joseph Scotti, Ph.D. 
May ‘95 - July '95

Aug. '94 - May '95
Volunteer - Sharpe Psychiatric Hospital, Weston, WV

Spent one day per week with a neuropsychologist working with a chronic inpatient population. Observed intake interviews, competency interviews, treatment staff meetings, and neuropsychological testing.

Supervisor: Martin Boone, Ph.D.

Vertical Team Member - School Consultation Project, Department of Psychology, West Virginia University, Morgantown, WV.

Assisted in case conceptualization and analysis, data graphing, and behavior computer coding for a one-year project funded by the West Virginia Developmental Disabilities Planning Council. This project provided services to students and adults with developmental disabilities. Supervisor: Joseph Scotti, Ph.D.

\section{Clinically-Related Experience}

Jan. '99

Dec. '98

April '98

Sept. '95, '96', '97

Nov. '96

Jan. ‘95 - May ‘95

Nov. '90 - Des. ‘92
Participant - Completed a training course on substance abuse and dependence taught by Drs. Lou Moffet and Dolores Gallagher-Thompson, staff psychologists at the VA Palo Alto Health Care System. Completion of this course met California licensing requirements for addiction training.

Participant - Completed a three day workshop on Action and Commitment Therapy at Lake Tahoe, California. This cutting-edge therapy is centered on treating clients with experiential acceptance/avoidance issues.

Presenter - Battered Women's' Shelter, Morgantown, West Virginia. Presented a synopsis of the current information regarding stalking behavior to staff. Emphasized assessment, prediction of dangerousness, and intervention strategies.

Supervisor - Department of Psychology, West Virginia University Worked on clinical interviewing skills with first-year graduates enrolled in a clinical interviewing course. Conducted weekly 1 1/2-hour sessions that included role-plays and videotaped reviews.

Presenter - Department of Psychology, West Virginia University Co-presented a case of PTSD treated with implosive therapy during departmental colloquia.

Teaching Assistant - Department of Psychology, West Virginia University Assisted with Behavioral Assessment II, a graduate assessment course. Responsibilities involved observing and providing feedback as students administered practice tests. Supervisor: Tracy Morris, Ph.D.

Crisis Hotline Counselor - Suicide and Crisis Service, San Jose, CA Received intensive crisis intervention training. Performed over 200 hours actual service. Received commendation citation from the Milpitas Police Department for outstanding response during a particular emergency. 
Aug. ' 82 - June ' 85
Resident Assistant - University of the Pacific, Stockton, CA Responsible for 350 freshmen and sophomore students. Maintained supportive environment in large dormitory, enforced University policies and regulations. Organized recreational activities and academic support groups. Responded to emotional and physical emergencies and mediated inter-resident disputes. Counseled students with academic and/or personal difficulties.

\section{Publications}

Westrup, D., Fremouw, W., Nakase-Thompson, R., \& Lewis, S. F. (in press). The psychological impact of stalking in female undergraduates. Journal of Forensic Science.

Westrup, D. (1998). Functional analysis of stalking behavior. In R. J. Meloy (Ed.), The Psychology of Stalking: Clinical and Forensic Perspectives. San Diego: Academic Press.

Westrup, D., \& Fremouw, W. (1998). Stalking behavior: A literature review and suggested functional analytic assessment technology. Aggression and Violent Behavior: A Review Journal, 3, 255-274.

Fremouw, W., Westrup, D., \& Pennypacker, J. (1997). Stalking behavior in a sample of college students. Journal of Forensic Sciences, 42, 666-669.

Westrup, D., Kalish, K. D., \& Masia, C. (1997, Winter). Successful treatment of PTSD in a MVA survivor: A case study. Disaster \& Trauma Currents.

Kalish, K. D., Westrup, D., \& Masia, C. (1997, Fall). MVA-related PTSD treated with flooding: Effective use of the paradigmatic model. Disaster and Trauma Currents, 5, 6-10.

Westrup, D., Keller, S., Nellis, T. \& Hicks, R. (1994). Arousability and bruxism in male and female college students. In R. L. Solso and H. H. Johnson (Eds.), My paper on this study was included in: Experimental psychology: A case approach (pp. 201-204). New York: HarperCollins College Publishers.

Westrup, D., Keller, S., Nellis, T. \& Hicks, R. (1992). Arousability and bruxism in male and female college students. Perceptual and Motor Skills, 75, 796-798.

\section{Conference Symposium Presentations}

Westrup, D. A Behavioral Approach to Stalking. In D. Westrup (Chair), R. A. Fein (Discussant), J. Reid Meloy (Co-presenter), K. Kienlen (Co-presenter), In Pursuit of Stalking. Symposium at the 106th annual meeting of the American Psychological Association, San Francisco, CA, August 1998.

Kalish, K., \& Westrup, D. The Paradigmatic Framework Model: Application with a Motor Vehicle Accident Survivor. In J. Scotti (Chair), S. Annan, S. Lewis, A. Rabalais, \& R Veneble (Co-presenters), Recent Research in Post-Traumatic Stress Disorder: Epidemiology and Treatment. Symposium conducted at the annual meeting of the West Virginia Psychological Association in Flatwoods, West Virginia, March 1998.

Westrup, D. Stalking at West Virginia University. In D. Kalish (Chair), Student Health Stalking Symposium, March 1998. 


\section{Paper Presentations}

Morris, T. L., Gorham, J., Cohen, S. H., Huffman, D., Null, J., Westrup, D., \& Wirth, O. (1995). "Fashion in the classroom: Effects of attire on students' perceptions of teacher credibility and competence". Paper presented at the meeting of the Eastern Communication Association, Pittsburgh, PA

Westrup, D., \& Cooper, R. (1993). “Applying the story model to juror decision-making: A response to juror bias". Masters thesis presented at the Spartan Psychological Research Colloquium, San Jose, CA.

Westrup, D., Keller, S., Nellis, T., \& Hicks, R. (1992). "Bruxism and arousal predisposition in college students”. Paper presented at the Spartan Psychological Research Colloquium, San Jose, CA.

Nellis, T., Keller, S., Westrup, D., \& Hicks, R. (1992). “Arousal predisposition and temporal mandibular joint disorder in college students". Paper presented at the Spartan Psychological Research Colloquium, San Jose, CA.

\section{Poster Presentations}

Westrup, D., Nakase Thompson, R., \& Fremouw, B. (1997). “Incidence and impact of stalking among female college students". Poster presented at the 31st annual meeting of the Association for the Advancement of Behavior Therapy, Miami, FL.

Westrup, D., Nakase Thompson, R., \& Fremouw, B. (1997). “Attachment style and stalking behavior of former intimates: A predictor?" Poster presented at the 31 st annual meeting of the Association for the Advancement of Behavior Therapy, Miami, FL.

Westrup, D., \& Kalish, K. (1997). “Successful treatment of PTSD in a MVA survivor: A case study”. Poster presented at the 31st annual meeting of the Association for the Advancement of Behavior Therapy, Miami, FL.

Frazer, N. L., Larkin, K. T., Robyn, S., Brown, S., Null, K., Spaulding, S., Westrup, D., \& Ciano, L. (1997). "Relations among cognitive affective, behavioral, and cardiovascular responses to stress". Poster presented at the annual meeting of the Society for Behavioral Medicine, San Francisco, CA

Fremouw, W. J., Westrup, D., \& Pennypacker, J. (1995). "Stalking behavior in a college sample”. Poster presented at the 29th annual meeting of the Association for the Advancement of Behavior Therapy, Washington DC.

Westrup, D., Keller, S., Nellis, T., \& Hicks, R. (1992). “Bruxism and arousal predisposition in college students". Poster presented at the annual meeting of the Western Psychological Association, Portland, OR.

Keller, S., Westrup, D., Nellis, T., \& Hicks, R. (1992). "Periodontal disease and arousal predisposition in college students". Poster presented at the annual meeting of the Western Psychological Association, Portland, OR.

Nellis, T., Keller, S., Westrup, D., \& Hicks, R. (1992). “Arousal predisposition and temporal mandibular joint disorder in college students". Poster presented at the annual meeting of the Western Psychological Association, Portland, OR. 


\section{Research Experience}

Jan. '97 - present

Aug. '94 - May '98

Aug. '96 - May '97

Aug. '96 - May '97

June '96 - Aug. '96

Dec. '94 - Dec. '96

April '93 - Nov. '93

June '92 - Nov. '92
Principal Investigator - Dissertation topic: "Experiential avoidance and alcohol dependence relapse." This prospective study examines emotional avoidance, coping, and environmental stressors as predictors of relapse among alcohol-dependent subjects. Data collection of both phases has been completed and the projected defense date is May of 1999.

Research Assistant - Conducted ongoing research on stalking behavior. This exploratory effort evolved into extensive examination of this behavior within a college population. The behavior's prevalence and impact was studied as well as the coping responses of victims. Responsibilities included project conceptualization, reviewing relevant literature, developing and administering a stalking behavior questionnaire to over 900 college undergraduates. Was also responsible for data coding, entry, and analysis. Principal Investigator: William Fremouw, Ph.D.

Principal Investigator - This project examined attachment style and dependent behavior as predictors of stalking behavior among former intimates. Responsibilities included literature review, questionnaire development and administration, data entry and analysis.

Research Assistant - Assisted with a prevalence study of trauma and psychosocial stressors among college students. Responsibilities were to help review relevant literature, formulate and help administer a questionnaire packet. Principal Investigator: Dusty Persels.

Research Assistant - Held a part-time, paid position with Survey Associates, a private practice survey research firm. Assisted with the implementation of community-wide surveys regarding the psychological and behavioral effects of traumatic events, such as technological accidents, disasters, and personal injury. Supervised by Joseph R. Scotti, Ph.D., and Tracy L. Morris, Ph.D.

Research Assistant - Served as a role-play confederate for an empirical study regarding the effects of family environment on psychophysiological response to stress. Principal Investigator: Kevin Larkin, Ph.D.

Principal Investigator - Conducted masters thesis empirical study that applied the story model to juror decision-making. Was solely responsible for all aspects of this project, including research design, data collection, coding, input and analyses.

Research Assistant - Employed by University of California, San Francisco's Human Development and Aging Program to assist with sixyear longitudinal study on stress and coping among Alzheimer's caregivers. Was trained to administer lengthy structured interviews in subjects' home environments. Also assisted with scheduling and coordination of subjects. Principal Investigator: Leonard Pearlin, Ph.D. 
Aug. '91 - May '92

Research Assistant - Assisted with a project examining bruxism and arousal predisposition in college students. Assisted in the formulation of a survey administered to approximately 800 college students to identify bruxers. Collected, coded and input data. Assisted with data analyses and interpretation. Principal Investigator: Robert Hicks, Ph.D.

\section{Teaching Experience}

Nov. '96, Feb. ‘97

Guest Lecturer - Forensic Psychology

Department of Psychology, West Virginia University, Morgantown, WV Provided guest lectures to two groups of psychology undergraduates.

Aug. '95 - Dec. '95

Instructor - Forensic Psychology

Department of Psychology, West Virginia University, Morgantown, WV Co-taught an undergraduate course in forensic psychology. Responsible for course development, curriculum, lectures, exam development and grading.

Supervisor: William Fremouw, Ph.D.

Aug. '94 - May '95 Instructor - Introduction to Psychology

Department of Psychology, West Virginia University, Morgantown, WV Responsible for lectures, quiz administering and scoring, final grading. Taught two classes of approximately 60 students per semester. Supervisor: Tracy Morris, Ph.D.

Jan. '92 - May '92 Graduate Lecturer - Elementary Statistics Department of Psychology, San Jose State University, San Jose, CA. Lectured as needed for classes of both undergraduates and graduates. Supervisor: James Asher, Ph.D.

Jan. '92 - May '93 Teaching Assistant - Elementary Statistics Department of Psychology, San Jose State University, San Jose, CA. Tutored student groups four times weekly, proctored and scored examinations, lectured in scheduled classes as needed. Supervisor: James Asher, Ph.D.

Aug. '85 - Dec. '85 Proctor - Intermediate French University of the Pacific, Stockton, CA. Assisted with oral drills and examinations.

\section{Membership in Professional Organizations}

American Psychological Association, 1993 - present

American Psychology - Law Society (Division 41, APA), 1996 - present

Society for a Science of Clinical Psychology section III of Division 12, 1993 - present

Association for the Advancement of Behavior Therapy, 1995 - present

Disaster and Trauma Currents, 1995 - present

Western Psychological Association, 1991 -1995 


\section{References}

Martin Boone, Ph.D.

Neuropsychologist, Assistant Professor

Department of Behavioral Medicine

West Virginia University

Weston, WV

(304) 296-1210

Barry Edelstein, Ph.D.

Professor, Department of Psychology

West Virginia University

Morgantown, WV 26506-6040

(304) 293-2001 ext. 661

William Fremouw, Ph.D., A.B.P.P.

Professor, Department of Psychology

West Virginia University

Morgantown, WV 26506-6040

(304) 293-2001 ext. 662

Jeff Hammond, Ph.D.

Chief of Psychology

Psychology Department

Federal Corrections Institute, Morgantown (304) 296-4416 ext. 285
Tamara Hoier, Ph.D.

Licensed Clinical Psychologist, Asst. Professor

Department of Behavioral Medicine

West Virginia University

Morgantown, WV 26505

(304) 291-5263

Dorene Loew, Ph.D.

Clinical Coordinator, National Center for PTSD

VA Palo Alto Health Care System

Palo Alto, CA 94304

(650) 493-5000 ext. 27161

Douglas Rait, Ph.D.

Director, Family Therapy Program

VA Palo Alto Health Care System

Palo Alto, CA 94304

(650) 493-5000 ext. 24697

Joan Ross, R.N., M.S., M.F.C.C.

Senior Supervisor, Family Therapy Program

VA Palo Alto Health Care System

Palo Alto, CA 94304

(650) 493-5000 ext. 25190 